\title{
La borrasca Filomena: características y estimación de daños en el arbolado de Madrid mediante imágenes de satélite
}

The storm Filomena: characteristics and damage estimation in Madrid's woodland through satellite imagery

\author{
María Eugenia Pérez González \\ meperez@ucm.es \\ José María García Alvarado \\ josemaga@ucm.es \\ María del Pilar García Rodríguez \\ mpgarcia@ucm.es \\ Departamento de Geografía \\ Universidad Complutense de Madrid (España)
}

\section{Resumen}

Las características de la borrasca Filomena y su impacto en el arbolado del Madrid se han analizado mediante mapas sinópticos, datos centenarios de nevadas e imágenes de satélite a diferentes escalas (Terra MODIS, Landsat 8 y Sentinel 2). Esta nevada histórica se extendió en enero de 2021 sobre la mitad de la superficie de la Península Ibérica, aunque sus consecuencias se agravaron ante la persistencia de la situación anticiclónica posterior, que mantuvo temperaturas superficiales en Madrid entre $-13^{\circ} \mathrm{C}$ y $-2,5^{\circ} \mathrm{C}$. El impacto en el arbolado, medido a través de imágenes de cambios en el NDVI, ha afectado al 11 \% de la cobertura vegetal invernal 
del municipio, con daños muy notables en Pinus pinea, P. halepensis y Quercus Ilex, tanto del viario urbano, como de los múltiples parques, jardines y espacios forestales de la ciudad.

Palabras clave: riesgo climático; nevada; impacto en arbolado; NDVI.

\begin{abstract}
The characteristics of the Filomena storm and its impact on the trees of Madrid are analysed using synoptic maps, centuries-old snowfall data and satellite images at different scales (Terra MODIS, Landsat 8 and Sentinel 2). This historical snowfall affected half the surface of the Iberian Peninsula in January 2021, and its consequences were aggravated by the persistence of the subsequent anticyclonic situation, which kept surface temperatures in Madrid between $-13{ }^{\circ} \mathrm{C}$ and $-2.5{ }^{\circ} \mathrm{C}$. The impact on the woodland, measured with images of changes in the NDVI, affected $11 \%$ of the winter vegetation cover of Madrid, with very notable damages to Pinus pinea, $P$. halepensis and Quercus ilex, both in the urban roads and in the city's many parks, gardens and forest spaces.
\end{abstract}

Key words: climate risk; snowfall; impact on woodland; NDVI.

\title{
1 Introducción
}

Madrid tiene el privilegio de ser una de las ciudades más arboladas del mundo (con unos 5700000 pies), sólo por detrás de Toronto, Atlanta, Londres y Birmingham; seguida en España a distancia por Barcelona, con una cifra menor (unos 1420 000) (Morcillo San Juan et al., 2019). Esta buena posición es el fruto de una larga trayectoria, que la ha dotado de numerosos espacios verdes, vinculados históricamente a posesiones reales (Casa de Campo y Monte de El Pardo) y a sucesivas acometidas municipales, del ayuntamiento y de particulares, hasta conformar los numerosos bosquetes, parques, jardines y callejero urbano "verde" de la ciudad.

La dimensión espacial del arbolado de Madrid desde el siglo XVIII al siglo XX ha sido analizada por Gómez Mendoza (1995 y 2003). Los diferentes espacios verdes se contemplaron al inicio como objeto ornamental, recreativo e higienista, apostando por especies que demandaran pocos cuidados y fuesen resistentes a la sequía estival. Es por ello que, en los parques más antiguos y amplios de la ciudad (Parque del Oeste, Dehesa de la Villa, lomas de La Elipa o de Vicálvaro, Retiro, Casa de Campo y El Pardo) se plantaron masivamente coníferas (géneros Pinus, Cupressus y Cedrus principalmente), que siguen siendo a día de hoy las especies dominantes, y que tras el paso de la borrasca Filomena se han visto seriamente dañadas. 
Desde el punto de vista conceptual, al inicio paisajístico e higienista, le siguió ya a mediados del XIX el ambientalista, una vez superadas en Madrid las posibilidades de traídas de agua a la capital, con las posibilidades de riego para las especies menos tolerantes a la sequía (Gómez Mendoza, 1995). En otras muchas ciudades del mundo, a lo largo del siglo XX se emprendió también una planificación "verde", en la que se van incorporando los beneficios de estos espacios en la salud, la ecología urbana, la conservación y la calidad de vida; primero en Estados Unidos y posteriormente en Europa (Coates, 1955; Blancher, 1963; Nicholson, 1979; Wild, 1981; Kweon, 1998). A modo de ejemplo, entre los años veinte y los noventa del pasado siglo Londres apostó ya por ir incorporando en la planificación urbana los conceptos de espacios abiertos, cinturón verde, sistema de parques interconectados, conservación de la naturaleza y cadenas verdes (Turner, 1992). Junto a estos enclaves "verdes" de la planificación urbana, desde la década de los setenta hasta la actualidad destacan además los estudios sobre los beneficios del arbolado en la amortiguación de la isla de calor urbana (Bernatzky, 1982; Almendros Coca, 1992; Bowler et al., 2010; Susca, 2011; Ng, 2012; Gago, 2013; Maimaitiyiming et al., 2014; Aram et al., 2019; Gál et al., 2021; entre otros muchos). También conforme crece con intensidad la población urbana y acompaña el consiguiente incremento térmico urbano, recobran fuerza los beneficios del arbolado urbano en la salud pública (Tzoulas et al., 2007; $\mathrm{Ng}$ et al., 2012; Du et al., 2021; etc.), y se torna como óptima medida para paliar los efectos del cambio climático (Alonso et al., 2011; Livesley, 2015). Entre las múltiples bondades del arbolado destaca su acción de filtro biológico, eliminando grandes cantidades de partículas y gases del aire $\left(\mathrm{PM}_{10}, \mathrm{O}_{3}, \mathrm{NO}_{2}, \mathrm{SO}_{2}\right.$ y $\left.\mathrm{CO}\right)$, por lo que mejora la calidad de ambientes urbanos contaminados (Nowak et al., 2006, 2013).

En gran parte de esta bibliografía se insiste en los beneficios que la infraestructura verde tiene para la calidad de vida en los ámbitos de mayor presencia, densidad y movilidad demográfica como son las ciudades, y su importancia tanto en los planes de reformas como en los nuevos desarrollos urbanísticos. En unos espacios como los urbanos, donde el valor del suelo es altamente especulativo, parecería antieconómico dedicar parte de ese suelo a espacio verde, pero la evolución normativa y la creciente preocupación ambiental y sanitaria han hecho que este elemento no solo recobre importancia, sino que se incluya en uno de los valores de cara al mercado de la vivienda, como buen estímulo de la producción del espacio urbano. Sin embargo, también es necesario señalar que estas infraestructuras verdes tienen algunos efectos negativos reales o potenciales para la población. La minimización o atemperación de la severidad de esos efectos requiere un manejo responsable y una especial atención en la 
planificación urbana. En relación con el arbolado urbano, no tanto en su forma de bosque, o parque, sino de arbolado callejero, los inconvenientes y riesgos potenciales son muy variados. Más allá del vuelco de troncos, de rotura de ramas, de invasión de ramas o raíces en edificios, agrietamiento de cimientos, de afecciona a la visibilidad viaria, etc., se encuentran otros potenciales efectos fitopatológicos (plagas, como la procesionaria, alergias diversas, etc.). De todo esto parece desprenderse que, si se balancean efectos positivos y riesgos, parece que los beneficios globales superan con creces a los riesgos y efectos negativos. Esto será así, mientras técnicos, y administraciones dediquen los suficientes recursos como para mitigar estos problemas (Calzada \& Iglesias-Díaz, 2016).

Quizá la más reciente re-semantización de la bondad medioambiental y de calidad de vida, de los espacios verdes, tanto en el medio rural como en el urbano, sea la incorporación del concepto "infraestructura verde" que llegará a abrir el camino para un mejor tratamiento, conservación, protección y aprovechamiento de lo que hasta entonces sólo, con ser mucho, se consideraba "patrimonio natural". Todo ello al hilo de la Estrategia de la Comisión Europea de Infraestructura Verde (Comisión Europea, 2014). La incorporación del patrimonio natural a la "Infraestructura Verde" se constata al haber supuesto un cambio jurídico importante que lleva a la modificación de la Ley 42/2007 de 13 de diciembre de Patrimonio Natural y de la Biodiversidad (Ley 33/2015, de 21 de septiembre). Al hilo de la nueva normativa jurídica, se ha definido la "Estrategia Nacional de Infraestructura Verde y de la Conectividad y Restauración Ecológicas", con el horizonte de 2050.

En Madrid, para dar cumplimiento a la citada Ley 33/2015, se incluye el "Plan de Infraestructura Verde y Biodiversidad", que tratará a su vez de paliar la elevada fragmentación medioambiental de la ciudad (García Alvarado et al., 2020). Por ello, el Ayuntamiento de Madrid ha previsto para los próximos diez años la plantación de 450000 árboles en el llamado "bosque metropolitano", que conectará perimetralmente el bosque de El Pardo al N-NW, la Casa de Campo al W, el anillo metropolitano al SW y el anillo verde del SE, para cerrar el municipio por el E, uniendo varios parques urbanos (Ayuntamiento de Madrid, 2021a). Este cinturón forestal supondrá una continuidad ecológica alrededor de la trama continua de la ciudad de Madrid, como preconiza, esta llamada en ocasiones "la M-40 verde" y amparada por el Madrid 360 (Rodríguez et al., 2018).

En este contexto de ciudad "verde" el arbolado de Madrid se ha visto seriamente castigado al inicio de 2021 por el paso de una fuerte borrasca, denominada por la AEMET Filomena, que 
dejó nevadas de gran intensidad. Las grandes cantidades de nieve caída y la extensión del territorio afectado en España han provocado notables pérdidas materiales, que repercuten principalmente en la agricultura y la ganadería (con daños directos en plantaciones, animales e infraestructuras), pero también han producido importantes daños en el arbolado, siendo muy notable en la ciudad de Madrid.

El objetivo inicial de este trabajo es conocer las características sinópticas de la borrasca Filomena y el alcance que la nevada ha dejado a su paso, a través de la información meteorológica y la aportada por diversas imágenes de diferentes satélites y sensores. De ellas se obtiene la evolución de la cobertura nival en la Península Ibérica durante el episodio Filomena (con imágenes Terra/MODIS), la extensión y temperatura superficial de la nieve en la Comunidad de Madrid (con Landsat 8 OLI/TIRS) y los cambios en la masa vegetal antes y después del paso de la borrasca, fundamentalmente arbórea (con Sentinel 2-A y 2-B).

La cantidad y continuidad de la nieve acumulada en el entorno urbano de Madrid al paso de esta borrasca hizo caer numerosos pies arbóreos y otros tuvieron que ser podados o talados durante las semanas posteriores a la caída de la nieve, con una pérdida considerable de masa vegetal. Por ello, el objetivo final de este trabajo es analizar las consecuencias del paso de la borrasca Filomena en el arbolado del municipio de Madrid, muy numeroso en el viario urbano, parques y en los dos enclaves forestales mediterráneos (Casa de Campo y Monte del Pardo). En estos predominan lógicamente especies perennifolias, que han sido las más afectadas por el impacto de la nevada en pleno invierno.

La teledetección resulta una herramienta muy útil para estudiar la vegetación. El hecho de contar con imágenes de satélite con diferentes resoluciones espaciales, temporales y espectrales permite hacer un seguimiento de la evolución de la vegetación a distintas escalas y durante diferentes estados fenológicos. Con los satélites de alta resolución espacial se pueden hacer estudios de detalle, de pequeñas áreas como jardines o parques urbanos. El disponer de una serie de imágenes casi continua facilita el seguimiento de los cambios, seleccionando además aquellos meses más útiles para cada tipo de vegetación, por ejemplo el otoño e invierno para diferenciar plantas caducifolias de perennifolias, el verano para discriminar los cultivos de regadío, etc. La alta resolución espectral, con numerosos canales tanto en el espectro del visible como en los infrarrojos, y la posibilidad de realizar operaciones con ellos, permite discriminar las zonas arboladas diferenciándolas de otros usos del suelo y de otros tipos de vegetación. En el caso que nos ocupa, el hecho de que la borrasca sucediera en enero y las imágenes 
seleccionadas posteriormente sean también de invierno ha permitido distinguir claramente la vegetación perennifolia y ver la pérdida de masa que ha sufrido. En próximos estudios, seleccionando imágenes de primavera y/o verano también se podría estimar la pérdida de vegetación en las especies caducifolias. No obstante, los posibles efectos sobrevenidos por causa de la congelación parcial o total de individuos que puedan afectar al conjunto del arbolado urbano no se han analizado en este trabajo, pues con un mayor intervalo temporal de análisis también se entremezclan nuevas actuaciones municipales encaminadas a sustituir parte del arbolado dañado, por lo que estos objetivos exceden los aquí planteados.

\section{2 Área de estudio}

La ciudad de Madrid se encuentra situada en el centro de la Península lbérica (40 25'00" $\mathrm{N}$ y $\left.3^{\circ} 42^{\prime} 00^{\prime \prime} \mathrm{W}\right)$, siendo su municipio central el de mayor tamaño $\left(605.77 \mathrm{~km}^{2}\right)$ y densidad, con una población residente de 3334730 de habitantes. Con una altitud media elevada (655 m), presenta la mayor altitud al Norte de la ciudad, en el eje Fuencarral Chamartín (744-735 m), y la más baja en el límite sur, en la Villa de Vallecas (554-551 m, junto al río Manzanares).

El municipio en su totalidad no sólo viene a ser ya casi el mismo perímetro que la ciudad de Madrid, sino que en algunos casos la continuidad urbana de la misma supera a éste (Figura 1). Se ha elegido el municipio de Madrid como área de estudio por su intensidad de ocupación urbana, y por ser una unidad de gestión y planeamiento de peso dentro del conjunto de la conurbación madrileña (García Alvarado et al., 2020).

Madrid se asienta en la campiña, área de transición entre la sierra de Guadarrama y la cuenca de Madrid, sobre materiales terciarios del neógeno, de carácter detrítico en el norte y centro (arcosas, arenas, arcillas y limos), y mayoritariamente de origen químico hacia el sur y sudeste (margas, yesos, margas yesíferas, sepiolita y sílex) (IGME, 1971), Tras la instalación y modelado posterior por parte de la red fluvial, las formas del relieve del municipio más destacadas están constituidas por pequeñas lomas y vaguadas alargadas, con dirección dominante N-S, que otros autores ya analizaron en su influencia al clima urbano de Madrid (Fernández García et al., 1996).

El municipio de Madrid está flanqueado al este por el río Jarama, tributario del Tajo por su margen derecha. Su principal afluente por la margen derecha, el Manzanares, lo atraviesa por el oeste, y junto a sus antiguos tributarios, los arroyos del Abroñigal (actual M-30-E) y Castellana-El Prado, mantienen la dirección dominante N-S, NW-SW, lo que configura la sucesión de barrios 
topográficamente elevados y deprimidos. Los pequeños arroyos que vierten a estos ríos (con dirección aproximada E-W) seccionan las pequeñas lomas de la ciudad, resultando un entramado urbano con más pendientes de lo que a priori le confiere la campiña y su aparente llanura.

Figura 1. Área de estudio

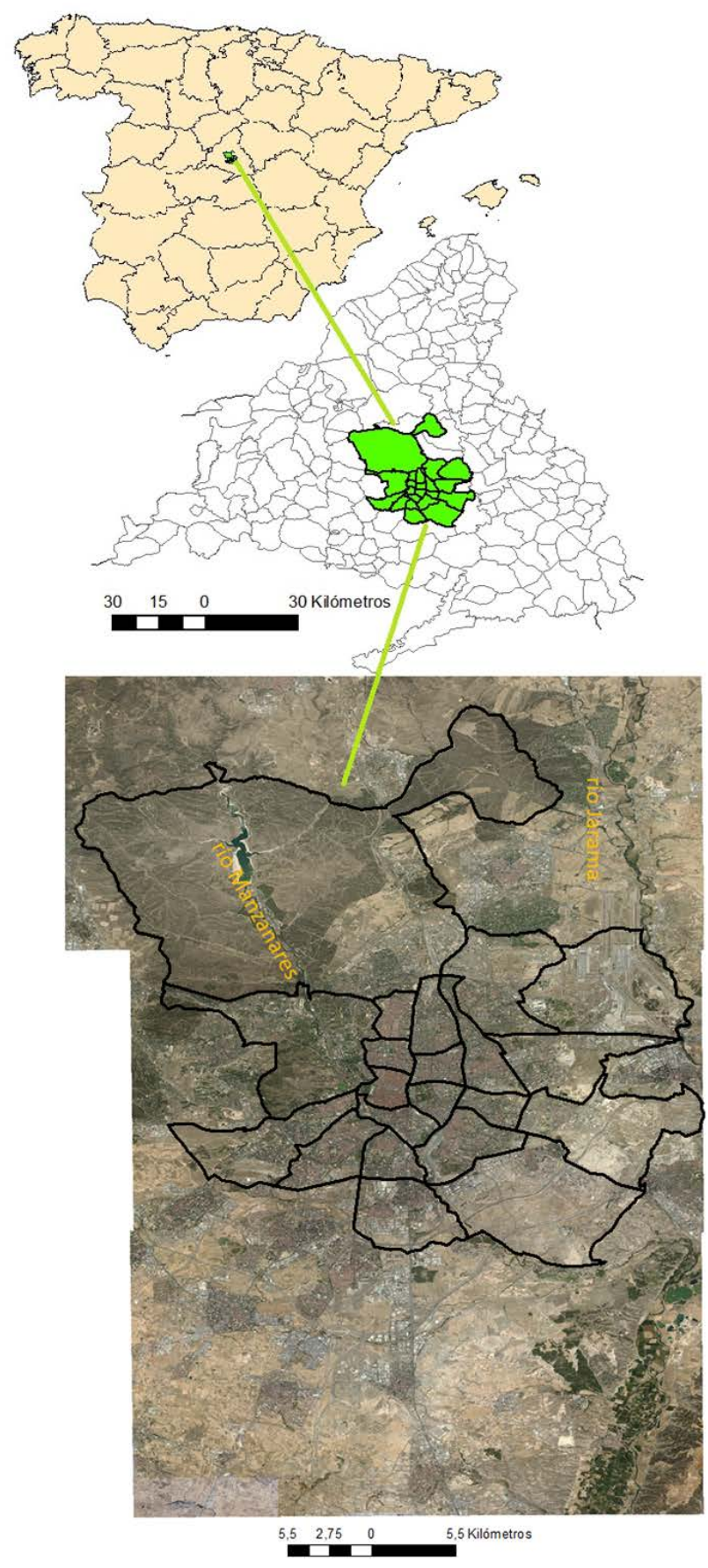

Fuente: elaboración propia a partir de bases cartográficas del IGN (provincial, municipal y de distritos) y mosaico de orfotos de las hojas 533, 534, 582 y 5559 (PNOA) 
El clima es mediterráneo de matiz continental, con unas temperaturas medias anuales, en el período $1981-2010$, entre $14,5^{\circ}-15^{\circ} \mathrm{C}$, con máximas en julio que rondan los $25,6^{\circ} \mathrm{C}$ y mínimas en enero entre $5.5^{\circ} \mathrm{C}$ y $6.3^{\circ} \mathrm{C}$, siendo relevante el gran contraste térmico diario y anual, con medias mensuales de las temperaturas máximas estivales entre $32^{\circ} \mathrm{C}-33,5^{\circ} \mathrm{C}$ y medias mínimas invernales entre $0,2^{\circ} \mathrm{C}-3,7^{\circ} \mathrm{C}$. La precipitación media es baja (371-428 mm), con una sequía estival de junio a septiembre y máximos equinocciales, siendo los meses de octubre, noviembre, diciembre y mayo los más húmedos (41-60 mm/mes).

El período con probabilidad de nevadas en Madrid del último siglo (1920-2020) se produce de octubre a abril, con un número de días medio anual reducido $(3,8)$, pero con máximos que llegan a 11 días/año (1941, 1950, 1978 y 2009) y otro 11 \% de años sin nieve (Figura 2).

Figura 2. Días de nieve en Madrid (1920-2020)

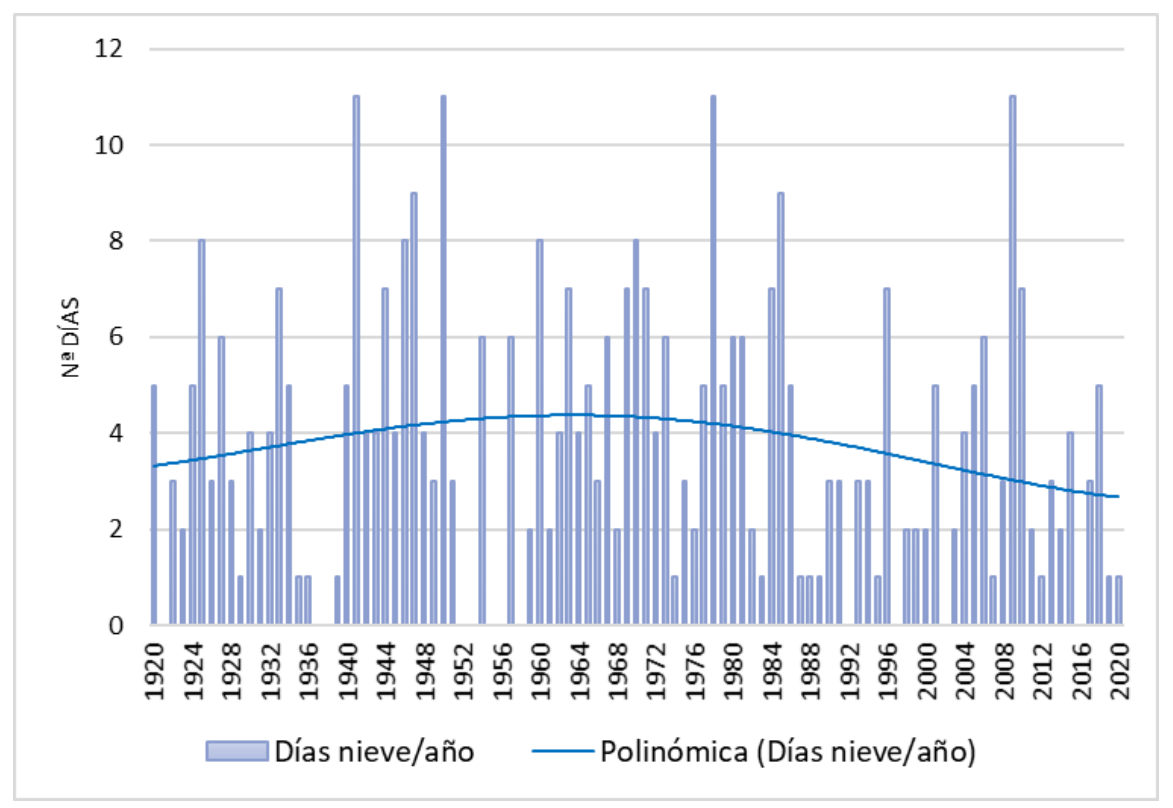

Fuente: elaboración propia a partir de datos de la AEMET

Por décadas, los pasados cuarenta y setenta fueron los que registraron más días de nevadas (59 y 52 respectivamente), y los que menos, los más recientes (2010-2020), y los pasados cincuenta (22 y 24 días/década de nieve respectivamente), por lo que en los diez últimos años evaluados, las nevadas han sido las menos frecuentes del siglo, con una duración anual entre 1 y 5 días. A su vez, se advierte una tendencia descendente en el número de nevadas al año desde los años ochenta a la actualidad, lo que ha hecho de Filomena una borrasca tan inusual, que ha puesto en evidencia lo vulnerable de los entornos urbanos a las grandes nevadas cuando suceden en ámbitos climáticos donde este meteoro es ocasional y la gran cantidad registrada durante el evento muy extraordinaria. 
La distribución estacional de la nieve en la ciudad de Madrid durante el último siglo (1920_ 2020) arroja un 80,6 \% de días de nevada en la estación invernal, seguida de la primavera (16\%), y en menor medida en otoño, con un 3,4\% (Tabla 1). El mes de mayor riesgo de nieve es enero (31\%) y el de menor octubre, con el 0,26\%, pues sólo ha sucedido una vez en un siglo de días de registro (en 1975).

Tabla 1. Distribución porcentual de días de nieve en Madrid por meses y estaciones (1920-2020)

\begin{tabular}{|c|c|c|c|c|c|c|}
\hline \multicolumn{3}{|c|}{ INVIERNO } & \multicolumn{2}{c|}{ PRIMAVERA } & \multicolumn{2}{c|}{ OTOÑO } \\
\hline \multicolumn{3}{|c|}{80,57} & \multicolumn{2}{c|}{16,06} & \multicolumn{2}{c|}{3,37} \\
\hline Dic & Ene & Feb & Marzo & Abril & Oct & Nov \\
\hline 22,02 & 31,09 & 27,46 & 11,92 & 4,15 & 0,26 & 3,11 \\
\hline
\end{tabular}

Fuente: elaboración propia a partir de datos de la AEMET

Los suelos del municipio de Madrid corresponderían a distintas unidades de luvisoles, cambisoles, regosoles, arenosoles y calcisoles. En el sureste dominan los gipsisoles y en las vegas de los ríos los fluvisoles. Pero la mayor parte de los suelos han desaparecido en la ciudad por sellado o se han transformado en antrosoles y tecnosoles.

Según Morcillo San Juan et al. (2019) el municipio de Madrid tiene aproximadamente 5700000 árboles, de los que 3700000 están en el casco urbano y unos 2000000 forman parte de espacios forestales pertenecientes al municipio y localizados fundamentalmente en El Monte de El Pardo, Soto de Viñuelas y una pequeña parte del Parque Regional del Sureste. En total, un $26 \%$ de la superficie municipal tiene cobertura arbórea.

Del conjunto arbóreo madrileño, algo más de la mitad está formado por especies perennifolias, con un claro predominio de pino piñonero (Pinus pinea, 27, 1\%), encina (Quercus ilex, 16,7\%), pino carrasco (Pinus halepensis, 7,2\%) y ciprés de Arizona (Cupresus arizonica, 4, 1\%), a lo que se le suman plátano de sombra (Platanus hybrida, 5,4\%), olmo de Siberia (Ulmus pumila, 4,1\%), y acacia del Japón (Sophora japonica, 2,6\%).

Otras especies frecuentes en el estrato arbóreo son: fresnos (Fraxinus angustifolia), quejigos (Quercus faginea), enebros (Juniperus oxycedrus), madroños (Arbutus unedo) alisos (Alnus glutinosa), sauces (Salix sp.), chopos (Populus alba y P. nigra), fresnos (Fraxinus angustifolia), tarays (Tamarix sp) y carrizales (Phragmites australis). En el estrato arbustivo: coscoja (Quercus coccifera), labiérnago (Phyllirea angustifolia), torvisco (Daphne gnidium), cornicabra (Pistacia 
terebinthus), madreselva (Lonicera sp.) romero (Rosmarinus officinalis), jara (Cistus ladanifer), cantueso (Lavandula stoechas), retama (Retama sphaerocarpa) (Comunidad de Madrid, 2020).

En el sureste del municipio aparecen especies gipsícolas (González Granados, 2011) entre las que destacan: Gypsophila struthium, Ephedra fragilis, Lepidium subulatum, Frankenia thymifolia, Herniaria fruticosa, Lithodora fruticosa, Thymus zygis y Th. lacaitae.

El arbolado de Madrid podría clasificarse en función de su inserción en el tejido urbano de la ciudad. Así, se encuentra el arbolado que forma parte de los grandes parques, considerando como tales los que tienen más de 100 hectáreas; que son por orden decreciente, la Casa de Campo (1 722,60 ha); Finca de Tres Cantos-Monte de Viñuelas (228,56 ha), Juan Carlos I (160 ha), Jardines del Buen Retiro (118 ha) y Madrid Río (101 ha). Un importante espacio verde arbolado, (más de 15000 ha) en forma de bosque, dehesa o jardines históricos, es el Monte de El Pardo, que si bien tiene un peso ecológico, ambiental y urbano en la ciudad de Madrid, no queda registrado en el inventario municipal al ser un monte de titularidad estatal, gestionado por Patrimonio Nacional, como espacio natural protegido. Por esta razón se deberá agregar a la cartografía del arbolado de Madrid (Figura 3).

Una segunda tipología de espacios verdes son las áreas ajardinadas de pequeño o medio tamaño insertos en la trama urbana. Muchos son parques urbanos que proceden de actuaciones desde los años ochenta, donde las directrices metropolitanas del planeamiento, los planes urbanísticos subsiguientes, eran reincidentes en la potenciación y conservación de las áreas con valores ambientales ya existentes (Terán \& Sánchez de Madariaga, 1999). Finalmente es importante señalar el denominado arbolado de alineación o de viario que cuenta, según inventario municipal, con más de 293000 ejemplares de 800 especies diferentes, entre las que predominan Platanus hybrida, Sophora japonica, Ulmus pumila, Robinia pseudoacacia, Acer negundo, Ligustrum japonica, Catalpa bignonioides, Pinus pinea, Celtis australis, Aesculus hippocastanum, Gleditsia triacanthos, Morus alba, Acer pseudoplatanus, Populus alba 'Bolleana, Ulmus campestris, Populus $\times$ canadensis, Melia azederach, Prunus cerasifera 'Pissardii', Ailanthus altissima, Populus alba, Morus nigra y Populus nigra. El predominio de especies caducifolias en el callejero de Madrid pueda deberse, tanto a la ventaja inicial de su rápido crecimiento, como a los beneficios que aportan al microclima urbano (Bernatzky, 1982; Bowler et al., 2010; Aram et al., 2019), amortiguando las altas temperaturas estivales y evitando sombras durante el invierno. Además, el amplio follaje proporcionado estacionalmente contribuye a bajar los valores de contaminación estival, especialmente de aerosoles (Nowak et al., 2013). 
Figura 3. Distribución del arbolado viario de gestión municipal por distritos.

(0) excepciones - El Monte de El Pardo, (1) Casa de Campo, (2) Finca de Tres Cantos,

(3) Parque de Juan Carlos, (4) Jardines del Buen Retiro y (5) Madrid Río

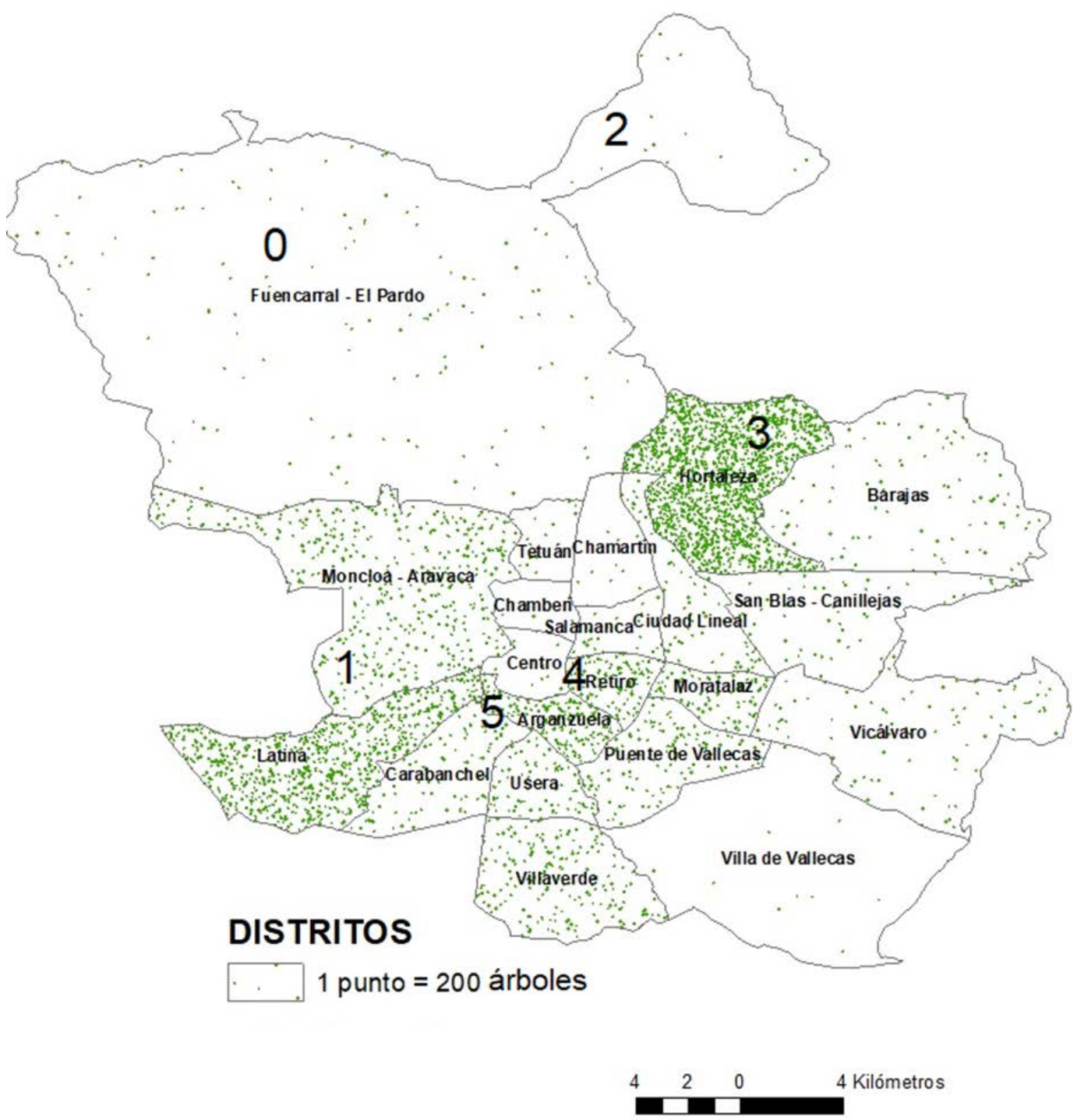

Fuente: elaboración propia a partir de Ayuntamiento de Madrid (2020)

Si bien las superficies arboladas son esenciales, el arbolado de alineación también tiene gran valor ambiental, pues al estar distribuido por áreas residenciales, la relación arbolado/habitante es, para lo positivo y lo negativo más estrecha que en los grandes y medios espacios, donde no está trabada con la función residencial o dormitorio. Arbustos, setos y céspedes, los aún muy escasos ejemplos de arquitectura verde, y retazos del llamado tercer paisaje, completarían el Madrid clorofílico. 
En este sentido, la mejor fuente de cartografía de los espacios verdes de Madrid, y su consiguiente arbolado, parecer ser la foto aérea para el detalle, si bien completado con los registros de otras fuentes de gestores municipales o autonómicos, pues esta distribución de competencias hace a las fuentes incompletas si se opta por algunas de ellas en exclusividad, pues ninguna recoge la totalidad del componente verde. El inconveniente estriba en la menor actualización temporal de la foto aérea, no siempre sincrónica con otros gestores cartográficos y documentales, lo que dificulta el rastreo del inventario ante sucesos extraordinarios de gran interés.

\section{Fuente y metodología}

El seguimiento de la situación meteorológica que ocasiona la borrasca Filomena se ha realizado a partir de los mapas sinópticos de superficie y 500 hPa del servidor web meteorológico alemán Wetterzentrale (2021) y los datos sobre altura de nieve registrados por la Agencia Española de Meteorología (AEMET, 2021).

La evaluación de la superficie nevada y análisis de los impactos ocasionados en el arbolado se aplica a diferentes escalas: una inicial pequeña, para conocer la extensión del manto nival en la Península Ibérica, hasta la grande, que ha permitido estimar su impacto en foresta urbana de Madrid. Por tanto, en función de la escala de trabajo se han adquirido y tratado diferentes imágenes (Tabla 2):

- Imágenes diarias del satélite Terra MODIS (Moderate-Resolution Imaging Spectroradiometer), sensor Terra, con 36 canales espectrales entre el visible, infrarrojo cercano, medio y térmico y con una resolución espacial variada de 250 m (bandas 1 y 2), 500 m (bandas 3 a 7 ) y 1000 m (bandas 8 a 36), se han utilizado para el análisis general del alcance de la cobertura de nieve en la Península Ibérica. Aquí se han seleccionado las combinaciones en color natural (RGB 1-4-3) para el seguimiento de la nubosidad, y sobre todo en falso color 3-6-7 (RGB) para discriminar y medir la cobertura de nieve, ya que esta combinación de canales espectrales permite diferenciar mejor la superficie cubierta de nieve de las nubes, al adquirir ambos elementos distinta coloración. En el caso de la imagen en color natural tanto las nubes como la nieve se visualizan en blanco, por lo que en los casos de extensa cobertura nival y amplia nubosidad estratiforme en capas bajas resulta difícil discriminar estas dos coberturas. Estas bandas espectrales se corresponden al canal azul (3: 459-479 $\mu \mathrm{m}$ ) e infrarrojos medios (6:

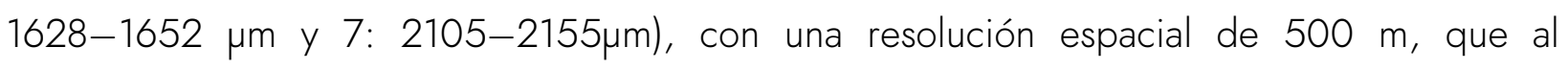
combinarlas con la banda 1 (visible, a 620-670 $\mu \mathrm{m}$ ) se obtiene una imagen con resolución 
final de $250 \mathrm{~m}$, ofreciendo imágenes con mayor detalle. La fuente de consulta y descarga de imágenes ha sido el portal Worldview de la NASA (NASA, 2021).

- Una imagen Landsat $8 \mathrm{OLI} / \mathrm{TIRS}$, con una resolución espacial de $30 \mathrm{~m}$ en el visible e infrarrojo cercano y un canal térmico a $100 \mathrm{~m}$, seleccionada a los pocos días del paso de la borrasca (11/01/2021) del servidor estadounidense Earthexplorer (USGS, 2021). En ella se analizó visualmente la cobertura máxima de nieve en la Comunidad de Madrid y áreas limítrofes y espectralmente los sectores arbolados libres de nieve o hielo mediante el índice de vegetación de diferencia normalizada (NDVI) (Tucker, 1979), por último se calculó la temperatura superficial a las 10 horas a.m. a partir de la banda 10, térmica del infrarrojo con 10.30-11.30 m, según la metodología de Valor y Caselles (1996) y Jiménez-Muñoz et al. (2014).

- Imágenes del satélite europeo Sentinel 2 MSI, con 10 y 20 m de resolución espacial en las bandas visibles e infrarrojas, seleccionadas antes y después del paso de la borrasca del servidor de descargas de Copernicus, de nivel 2 de procesamiento (Copernicus Sentinel Hub, 2021). Se han utilizado las imágenes de los dos satélites Sentinel 2 MSI, 2-A y 2-B, con la finalidad de aprovechar al máximo la disponibilidad de imágenes multiespectrales de resolución alta y media (cada 5 días con ambos) en un episodio de corta duración.

En estas imágenes se han analizado las diferentes coberturas del suelo del municipio de Madrid y las variaciones de la vegetación mediante índices y tratamientos digitales, idóneos también en la detección de la biomasa vegetal de ámbitos urbanos (Krüger et al., 2018), que son:

o Combinación de bandas en falso color natural (RGB 11-8-4) y falso color infrarrojo (RGB 8-4-3), correspondientes a los canales: infrarrojo medio (11), próximo (8) y visibles (rojo-4 y verde-3).

o Índice de vegetación de la diferencia normalizada (NDVI) (Tucker, 1979) es el cociente entre la diferencia de los valores espectrales de los canales del IR cercano y del rojo y la suma de ambos: (IRc - rojo)/(IRc + rojo). En el satélite Sentinel 2 estos canales corresponden a las bandas 8 y 4, por lo que el NDVI es: (B8 - B4) / (B8 + B4). Del conjunto de valores del NDVI ( \pm 1 en este índice normalizado) los negativos se corresponden con agua y nieve, mientras que a partir del umbral de 0,1 se identifica la respuesta de la cubierta vegetal y de 0,5 la vegetación densa (Holben, 1986). Por ello, el NDVI se utiliza principalmente para resaltar las áreas con alta actividad clorofílica frente a 
aquellas que no la tienen, por lo que resulta muy útil para cartografiar los distintos tipos de vegetación, analizar la evolución de la misma y su estado de conservación.

- Imágenes de cambios entre los valores de NDVI de febrero de 2020 y los de 2021. La imagen de cambio se calcula a partir de las diferencias entre las dos imágenes escogidas, resaltando el cambio que excede un umbral, aquí el $10 \%$ del valor del píxel (Hussain et al., 2013). El resultado es una imagen temática donde las celdas con pérdida de actividad clorofílica o de la superficie foliar aparecen en rojo y los incrementos en verde. Se ha optado por seleccionar estas fechas para recoger las diferencias en la reflectividad de la biomasa vegetal de dos inviernos próximos, antes y después del paso de la borrasca Filomena, detectando el daño provocado por la borrasca en la vegetación perennifolia. Los cambios serán debido básicamente a la caída de arbolado o parte del ramaje, pero podrían incluir otras causas menores.

Tabla 2. Selección de imágenes de satélite utilizadas.

\begin{tabular}{|c|c|c|c|c|}
\hline IMÁGENES & FECHA & $\begin{array}{c}\text { ÁREAS ANALIZADAS } \\
\text { AFECTADAS POR NIEVE }\end{array}$ & $\begin{array}{l}\text { BANDAS } \\
\text { UTILIZADAS }\end{array}$ & $\begin{array}{l}\text { RESOLUCIÓN } \\
\text { ESPACIAL (m) }\end{array}$ \\
\hline Terra/MODIS & $\begin{array}{c}\text { Diarias del } \\
6 / 01 / 2021 \text { al } \\
24 / 01 / 2021\end{array}$ & Centro peninsular español: & $\begin{array}{l}1-4-3 \\
3-6-7\end{array}$ & $\begin{array}{c}250 \text { (Visible) } \\
500 \text { (IRc) } \\
1000 \text { (IRT) }\end{array}$ \\
\hline $\begin{array}{l}\text { Landsat } 8 \\
\text { OLI/TIRS }\end{array}$ & $12 / 01 / 2021$ & $\begin{array}{c}\text { Comunidad de Madrid } \\
\text { (Escena 201/032) }\end{array}$ & 1 a 7,10 y 11 & $\begin{array}{c}30 \text { (Vis, IRc e IRm) } \\
100 \mathrm{~m}(\text { IRT) }\end{array}$ \\
\hline $\begin{array}{c}\text { Sentinel/2A y } \\
\text { 2B MSI }\end{array}$ & $\begin{array}{c}6 / 01 / 2021 \\
11 / 01 / 2021 \\
18 / 01 / 2021 \\
23 / 02 / 2020 \\
27 / 02 / 2021 \\
\end{array}$ & $\begin{array}{l}\text { Municipio de Madrid } \\
\text { (escena 30TVK) }\end{array}$ & 1 a 48,11 y 12 & $\begin{array}{c}10 \mathrm{~m} \text { (Vis e IRc) } \\
20 \mathrm{~m}(\mathrm{IRm})\end{array}$ \\
\hline Fotos PNOA & 2016 & Hojas 533, 534, 559 y 582 & Color natural & $50 \mathrm{~cm}$ \\
\hline
\end{tabular}

Fuentes: NASA (2021), USGS (2021), Copernicus Sentinel Hub (2021) \& IGN (2021)

Junto a estas fuentes y metodologías señaladas se desarrolla igualmente una aproximación al conocimiento de los espacios verdes urbanos en Madrid de tipo cartográfico, documental, bibliográfico y estadístico. Se utilizarán fuentes cartográficas y estadísticas, centradas sobre todo en el Banco de Datos del Ayuntamiento de Madrid (2020). Con ellas se ha elaborado una cartografía temática de base distrital sobre dos aspectos esenciales que permiten vincular vulnerabilidad y daño del fenómeno meteorológico estudiado: espacio verde urbano y arbolado.

Como problema metodológico esencial debe señalarse la enorme dificultad para valorar el conjunto de espacios verdes y arbolado por las fuentes, que entendemos son especialmente complejas en una ciudad como Madrid. En esta ciudad la infraestructura verde intraurbana en su 
rica variedad de formas (desde jardines históricos, montes, hasta el más humilde seto) está vinculada a numerosas competencias y, en consecuencia esta variedad de gestión, producción y distribución de la información es la que no permite tener una información homogénea. $\operatorname{Vr}$ gr: grandes y pequeños espacios verdes, rústicos, forestales o ajardinados de Patrimonio Nacional (Monte de El Pardo), Comunidad de Madrid, Ayuntamiento, patronatos o privados (jardines de los museos Romántico, Cerralbo, Sorolla, Ciudad Universitaria, etc.), Ministerio de Defensa (Jardines del Cuartel General del Ejército de Tierra), a lo que se añaden múltiples barrios o colonias cerradas con espacios verdes privativos, etc. De todas las fuentes disponibles elegimos la del Ayuntamiento de Madrid, como fuente principal, en tanto es la unidad político administrativa coincidente con el perímetro del área de estudio. No obstante, debe señalarse que la circunscripción a los datos del inventario municipal puede dar una imagen infravalorada del capital verde de la ciudad, pues no incluye el arbolado gestionado por otras titularidades cuya información es de difícil acceso.

Los actuales planes de Infraestructura Verde de Madrid, Bosque Metropolitano, y Madrid 360, han sido también una buena referencia para consulta de cartografía e información a este respecto. Además de estas referencias estadísticas, el trabajo de campo ha permitido recopilar numerosas fotografías de los daños, especialmente en el arbolado, y contrastar la verdad terreno con los resultados obtenidos.

\section{Resultados y discusión}

\subsection{Formación y desarrollo de la borrasca Filomena}

Desde el punto de vista meteorológico, la intensa nevada se produce por la conjunción y sucesión de varios episodios; se inicia con la entrada previa de aire ártico marítimo muy frío, entre los días 31 de diciembre de 2020, que torna a polar continental el 6 de enero del 2021 (Figuras $4 a$ y 4b), seguida de la formación y profundización de una borrasca atlántica entre Madeira y Golfo de Cádiz, que dejó un fuerte temporal de lluvia y viento en Canarias y el Sur peninsular (días 6 y 7/01/21), para adentrarse hacia el centro y nordeste de la Península los días 8 y 9 (Figuras 4c y 4d), dejando grandes cantidades de nieve: un gran manto no recordado en muchas décadas, por lo que bien puede clasificarse de histórica. En definitiva, la borrasca Filomena, procedente del SW, traslada gran cantidad de humedad que al contacto con el aire muy frío de la Península precipita en forma de nieve, con registros extraordinarios en cantidad y extensión. 
Una vez retirada la borrasca el día 10, le siguió una situación anticiclónica (Figuras 4 e y 4 f) con ola de frío y valores térmicos extremadamente bajos que permitieron mantener el manto nivoso congelado durante unos diez días, hasta la entrada de otra borrasca por el W, el día 19-01-2021, de componente oeste, más cálida y con precipitaciones moderadas que acabaron fundiendo en pocos días la nieve y hielo restante. Sin embargo, el paso de esta borrasca que acaba con los restos del manto nival no dio lugar a las inundaciones previstas, en buena parte por las múltiples actuaciones municipales encaminadas a retirar toneladas de nieve en el entorno urbano de Madrid y por escasas precipitaciones posteriores.

En síntesis, esta sucesión de tipos sinópticos, que ha condicionado la gran cantidad de nieve registrada sobre el centro peninsular durante el episodio de Filomena, puede resumirse en tres etapas: inicial, acumulación nival y estabilidad posterior, que se han producido con los siguientes valores de altura geopotencial a 500 hPa y presión en superficie:

- Inicial: 5400-5480 m y presión próxima a la normal (Figuras 4a y 4b)

- Acumulación nival: 5320-5400 m y 1005 hPa al paso de la borrasca (Figuras 4c y 4d)

- Estabilidad posterior y temperaturas gélidas: 5680 m y 1025-1030 hPa (Figuras 4 e y 4f) 
Figura 4. Resumen de tipos de tiempo que condicionan la nevada extraordinaria de la borrasca Filomena en el centro y nordeste peninsular
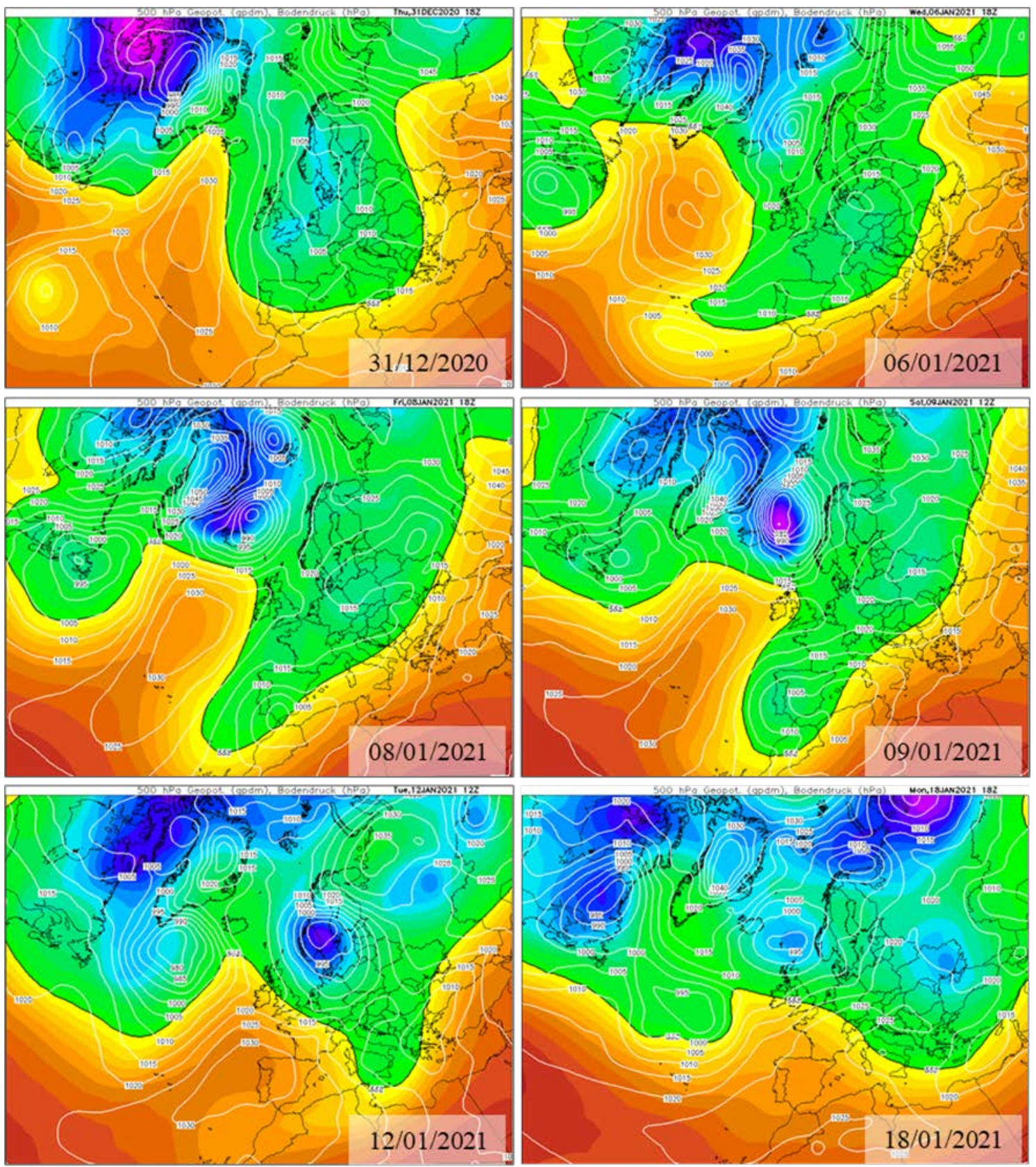

Data: CFS reanalysis $0.500^{\circ}$

(C) Wetterzentrale

www.wetterzentrale.de

476480484488492498500504508512516520524528532536540548552556560564568572576580584588592598600

Fuente: elaboración propia a partir de Wetterzentrale (2021)

Los valores registrados en la Península Ibérica por la AEMET durante este episodio rondan entre 30 y $50 \mathrm{~cm}$ de nieve, pero las cifras más altas no tienen precedentes constatados en muchas estaciones no montañosas y, además, es la primera vez que se dispone de imágenes de satélite con la suficiente resolución espacial, espectral y temporal para observar la superficie ocupada por la nieve durante más de diez días, lo que la sitúa como la nevada más extensa de las últimas décadas (Tabla 3). Debe precisarse que, aunque se disponen de imágenes de satélite desde los 
años setenta para la observación terrestre, la alta resolución temporal y espectral de las imágenes Terra MODIS y su actual resolución espacial en dos canales a $250 \mathrm{~m}$ ha permitido el seguimiento diario de la nevada dejada por la borrasca Filomena que otros satélites más antiguos no lo permitieron.

\section{Tabla 3. Valores de precipitación y altura de nieve durante los días 8 y 9/01/2021}

\begin{tabular}{|c|c|c|c|}
\hline NOMBRE, PROVINCIA & ALTITUD $(\mathrm{m})$ & PRECIPITACIÓN $(\mathrm{mm})$ & $\begin{array}{c}\text { NIEVE } \\
\text { ESTIMADA } \\
(\mathrm{cm})\end{array}$ \\
\hline Fraga, Huesca & 170 & 45.2 & 44.4 \\
\hline Cabacés, Tarragona & 363 & 58.2 & 57.4 \\
\hline Villafranca, Castellón & 1131 & 49.6 & 49.6 \\
\hline Alcañiz, Teruel & 334 & 41.4 & 41.4 \\
\hline Guadalajara & 721 & 34.4 & 34.4 \\
\hline Retiro, Madrid & 667 & 52.9 & 52.9 \\
\hline Barajas, Madrid & 609 & 38.2 & 38.2 \\
\hline Alto de Los Leones, M & 1532 & 35.6 & 35.6 \\
\hline Villanueva de la Cañada & 641 & 34.3 & 34.3 \\
\hline Torrelodones, Madrid & 879 & 30.6 & 30.6 \\
\hline Toledo & 515 & 55.4 & 51 \\
\hline
\end{tabular}

Fuente: AEMET (2021)

En los archivos históricos y efemérides de AEMET se han registrado otras nevadas intensas en Madrid, con una altura de nieve superior a los $20 \mathrm{~cm}$ en las décadas de los cincuenta y setenta del pasado siglo, siendo destacadas las de 6-12-1950, 27-01-1952 y 8-03-1971, con unos $30 \mathrm{~cm}$, y de 29-12-1977, con 22 cm. Otros años han sobresalido por el elevado número de días de nieve, hasta 11 en Madrid-Retiro el 4 \% de los años. La nevada más duradera ha sido de 8 días, en enero de 1941, y en fechas recientes, sólo destaca la de diciembre de 2009, con 5 días y una altura máxima de $15 \mathrm{~cm}$. Por tanto, bien puede afirmarse que los registros dejados por Filomena en dos días son en altura y extensión los más elevados en al menos el último siglo.

A lo largo de período 1920-2020 la distribución de nevadas no parece mostrar un patrón claro en cuanto al número máximo de días de nevada al año y años sin nevadas, ni a su frecuencia estacional. Sin embargo, los días de nevadas al mes sí se han reducido en las últimas décadas, no habiéndose producido nevadas de más allá de 5 días/mes desde 1997, siendo ahora más frecuentes las de 1 o 2 días/mes, registrándose las más duraderas con anterioridad a 1984.

Al tratar de conocer si estas nevadas extraordinarias se producen asociadas a unos tipos de tiempo concretos se advierte bastante variabilidad por fechas y años, pero sí parecen concurrir con frecuencia la entrada previa de aire muy frío (ártico o continental) con la formación de una borrasca al sur que alcanza buena parte de la Península. En todos los casos, la borrasca arrastra 
gran humedad, bien del Golfo de Cádiz o del Mediterráneo, que al chocar con la masa fría del interior favorece las nevadas más copiosas. Para el mantenimiento del manto nival se requiere lógicamente temperaturas muy frías y estabilidad atmosférica posterior, por lo que estas condiciones son más frecuentes durante el invierno, de modo que las nevadas de otoño o primavera tendrán más limiłada la permanencia nival fuera de las áreas de montaña. En cualquier caso, lo extraordinario es la sucesión de los tipos de tiempo señalados en pleno invierno, pues, aunque el tipo anticiclónico sea el más recurrente en invierno del interior peninsular (Fernández García, 1986) y el condicionante atmosférico principal de la alta contaminación de Madrid (Cañada Torrecilla, 2017), es poco frecuente que confluya con borrascas muy intensas. Durante el episodio Filomena una de las pocas ventajas en la ciudad, más allá del aporte adicional de agua, ha sido la brusca reducción de la contaminación atmosférica $\left(\mathrm{PM}_{2,5}, \mathrm{PM}_{10}, \mathrm{NO}_{2}\right.$ y $\left.\mathrm{SO}_{2}\right)$ provocada ante la paralización del tráfico rodado durante varios días a consecuencia de la acumulación y congelación posterior de la nieve.

\subsection{Características y extensión de la nevada al paso de la Borrasca Filomena}

La primera consecuencia de la borrasca Filomena fue la extraordinaria nevada, tanto en extensión como en espesor, que cubrió una gran parte de la España peninsular entre los días 7 y 10 de enero de 2021. Las observaciones de diferentes estaciones han señalado un espesor promedio entre 30 y 50 cm, dándose los máximos de áreas no montañosas en Tarragona (Cabacés, 57.4 $\mathrm{cm})$, Madrid capital $(52,9 \mathrm{~cm})$ y Toledo $(51 \mathrm{~cm})$, algo totalmente inusual (Tabla 3).

La aproximación general sobre la extensión de nieve alcanzada en la Península lbérica tras el paso de la borrasca Filomena puede seguirse a través de las imágenes del satélite Terra/MODIS (Figura 5). La interpretación visual en falsos colores resulta muy expresiva, especialmente al combinar los canales visibles e infrarrojos medios. De los muchos falsos colores posibles, la combinación de bandas 3-6-7 (R-V-A), discrimina fácilmente la nieve en rojo brillante, diferenciándola fácilmente de la nubosidad, en tonos blanco-anaranjados y de la superficie libre de nieve, en verde. También el patrón espacial aborregado de las nubes cumuliformes, más anaranjadas o próximas al rojo al alcanzar en su techo los valores térmicos más bajos, se discriminan con claridad del manto nival más homogéneo o bien adaptado a la topografía (Figura 5).

La extensión máxima alcanzada fue de 256000 km², el 11 de enero de 2021, fundiéndose lenta y progresivamente por los valles y cuencas del Ebro, Júcar, Duero, Segura y finalmente del Tajo, hasta desaparecer casi por completo el 20-21 de enero, al paso de una borrasca del W, sin 
mucha precipitación, pero con una subida notable de las temperaturas, que rompió la intensa inversión térmica de superficie, y con ella las temperaturas anormalmente bajas. De este modo, la nieve en el interior peninsular desaparece del valle del Ebro a los 3-5 días, gracias a su menor espesor $(<30 \mathrm{~cm})$, mayor insolación diurna, al ser una cueca muy abierta y menor pérdida radiativa nocturna, dada su menor altitud. El manto nival se mantuvo entre 4-8 días en el alto Júcar y Tajo, más angostos; hasta permanecer en gran parte de las dos mesetas afectadas por la nevada, en la Ibérica y en las Sierras de Cazorla y del Segura, hasta 12 días (Figura 5).

Figura 5. Imágenes MODIS/TERRA, combinación RGB 3-6-7
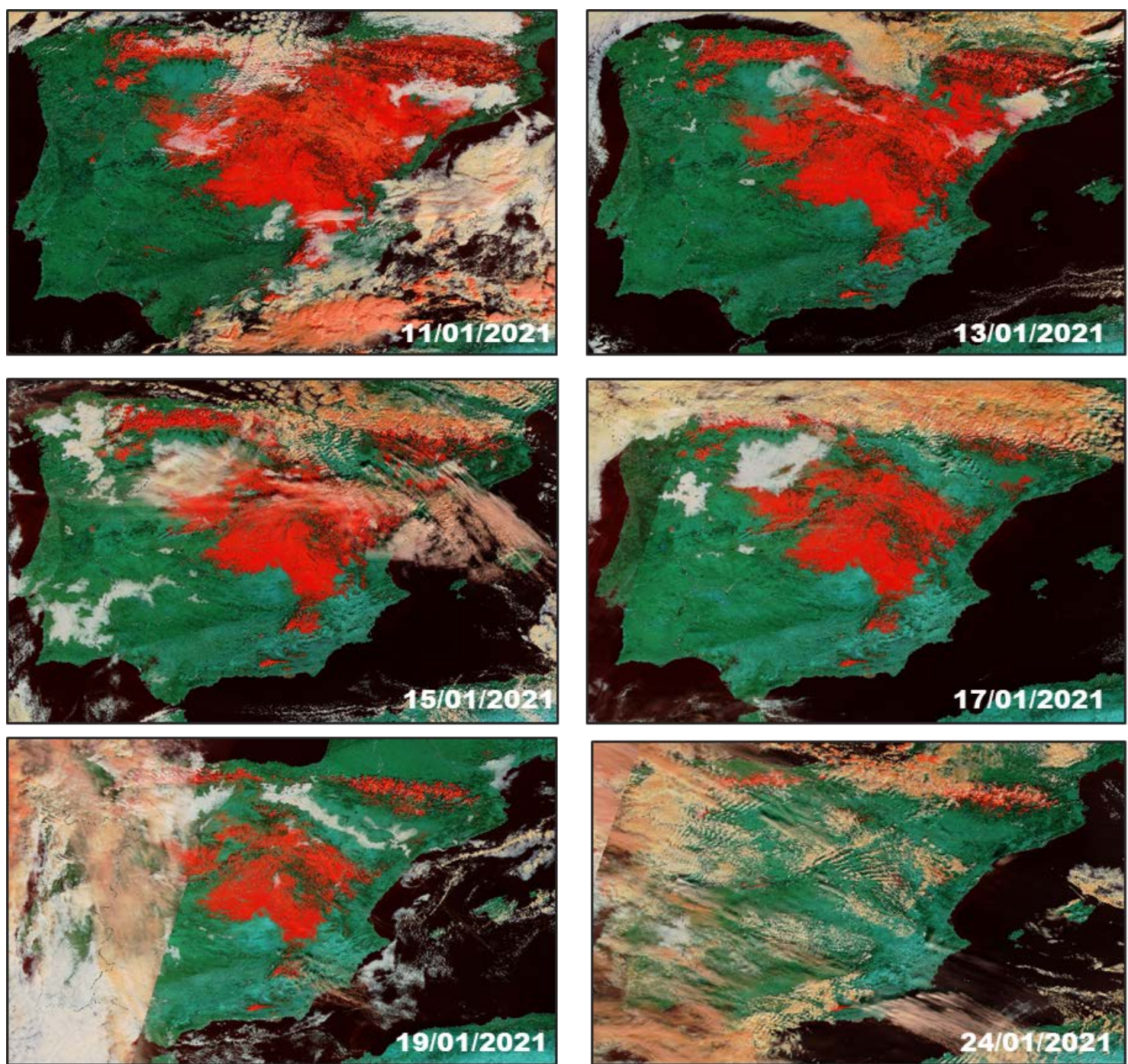

Fuente: NASA (2021) y elaboración propia

La borrasca Filomena cruzó la Península en forma de parábola, con una trayectoria SE-centro-NE. En la Comunidad de Madrid el espesor y manto nival fue menos intenso en la sierra y piedemonte que en los sectores de menor altitud, alcanzándose los máximos en la ciudad y 
mitad sur-sudeste de la Comunidad (Alto De Los Leones a 1532 m, con 35,6 cm y en MadridRetiro a $667 \mathrm{~m}, 52,9 \mathrm{~cm}$, Tabla 3).

Con mayor detalle, la imagen Landsat del 11/01/2021 ha permitido identificar los sectores cubiertos y libres del manto nival en la Comunidad de Madrid. Estos últimos se limitan a las aguas de los embalses y fluviales, cuenca media y baja del río Lozoya (al norte de la C.M.); sectores de la vertiente norte de la Sierra de Guadarrama (al NW-W), cuenca alta del río Alberche (al SW), edificaciones y parte del arbolado (Figura 6a).

Figura 6. Imagen Landsat 8, 11/01/2021:

imagen en color natural RGB 4-3-2(a) y temperatura superficial (b)

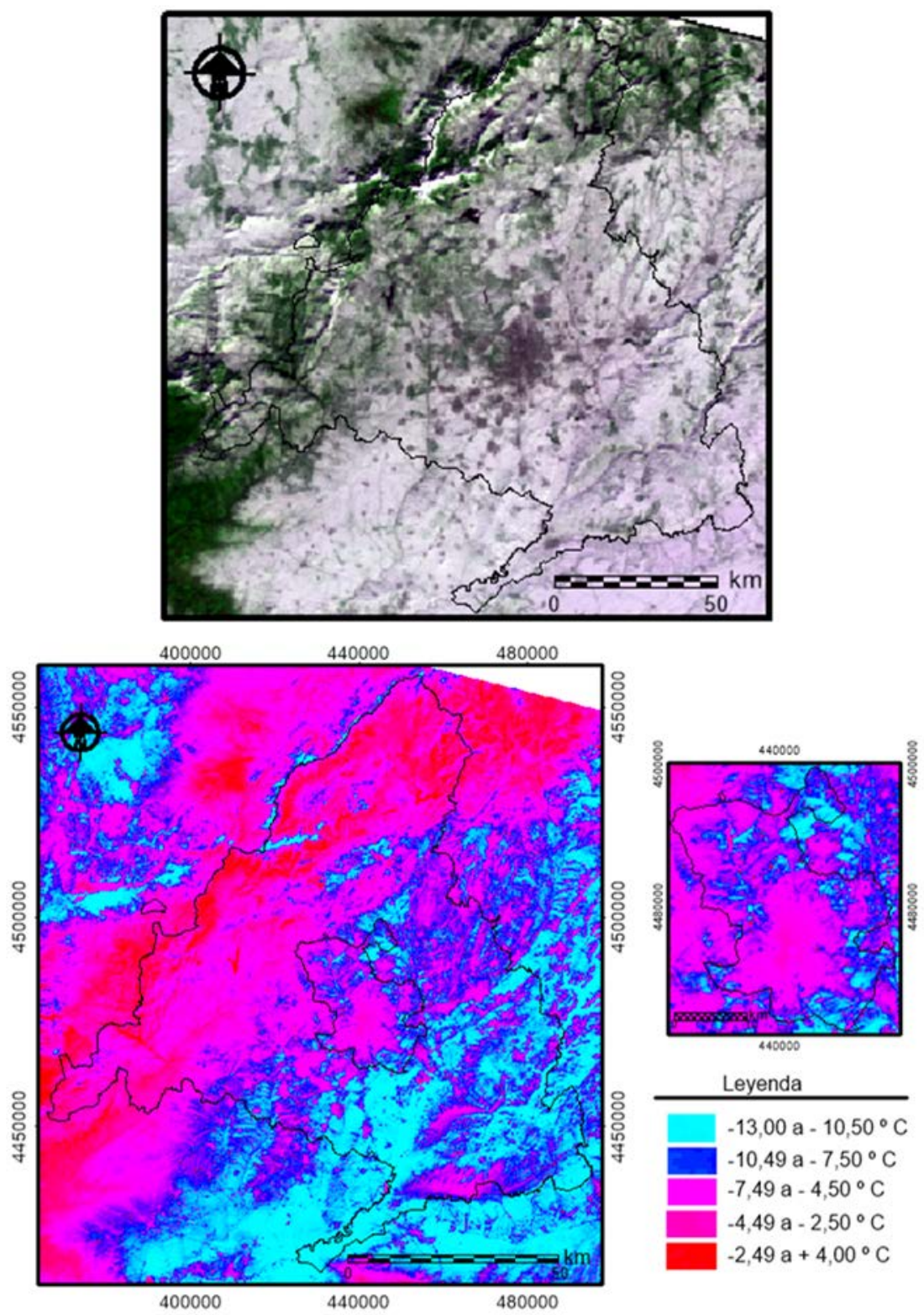

Fuente: elaboración propia y USGS (2021) 
Las temperaturas superficiales medidas en esta misma fecha muestran la notable inversión térmica NW-SE de los días posteriores al paso de filomena, con valores en la Sierra entre $-2,5^{\circ} \mathrm{C}$ y $4^{\circ} \mathrm{C}$, intermedios en la campiña, inferiores a $-7,5^{\circ} \mathrm{C}$ hacia el sur-sudeste, y otros enclaves menores, con $-7,5^{\circ} \mathrm{C}$ a $-13^{\circ} \mathrm{C}$.

En el municipio de Madrid las temperaturas oscilaron de las mínimas, $-11^{\circ} \mathrm{C}$ y $-10{ }^{\circ} \mathrm{C}$, en las áreas forestales de El Pardo, Monte de Viñuelas, Casa de Campo y suelos desnudos del Sur (tonos cian), a las menos bajas del distrito centro, con $-3,5$ a $-5{ }^{\circ} \mathrm{C}$ (tonos rosado-rojizo), con algunos sectores a $-2,5^{\circ} \mathrm{C}$. Son las aguas superficiales de estanques, embalses o corrientes fluviales las que tienen temperaturas menos rigurosas, entre $0^{\circ} \mathrm{C}$ y $-1,5^{\circ} \mathrm{C}$ (en rojo). Con temperaturas intermedias, durante la ola de frío, destaca una orla metropolitana discontinua con $-7,5^{\circ} \mathrm{C} \circ-8^{\circ} \mathrm{C}$ (tonos azulados), registrándose los valores urbanos más fríos al Norte (Fuencarral y Manoteras), con $-7^{\circ} \mathrm{C}$ a $-6^{\circ} \mathrm{C}$, en las posiciones de mayor altitud (Figura 6b). Durante el episodio frío tras el paso de Filomena, el municipio de Madrid mantuvo temperaturas superficiales negativas durante más de una semana. No obstante, pese a los valores excepcionalmente fríos alcanzados esos días, se sostuvo el patrón térmico de la "isla de calor" de Madrid, con los valores menos rigurosos en el centro, y los más bajos, en los espacios forestales y en los distritos más elevados de la ciudad (Fernández García et al., 2016). Estas temperaturas más bajas de los enclaves verdes urbanos (Bernatzky, 1982; Maimaitiyiming et al., 2014; Lemus-Canovas et al., 2020), excepcionalmente bajas en estas fechas, tendrá un claro impacto negativo en la foresta del municipio de Madrid.

\subsection{Estimación de daños en el arbolado mediante imágenes de satélite}

Como se viene señalando, la borrasca Filomena ha ocasionado daños diferenciales en función de la variedad morfológica y fisiológica de las especies que forman el patrimonio verde de la ciudad. Sirva como aproximación a la realidad verde previa a la irrupción del evento Filomena dos indicadores, uno la superficie de espacio verde, y otro el arbolado.

El Ayuntamiento de Madrid cuenta en su inventario de 2019 con algo más de 4000 hectáreas de biomasa vegetal, distribuidas por los diferentes distritos urbanos de forma desigual, lo que supone inicialmente el $6.6 \%$ del municipio (Figura 7). No obstante, a esta cifra hay que sumarle la superficie verde gestionada por Patrimonio Nacional de El Monte de El Pardo, ubicado en el distrito de Fuencarral-El Pardo, que supone casi el $40 \%$ de la superficie del municipio de Madrid. Con una cubierta vegetal extendida por 11356 ha (cerca del $40 \%$ del distrito), el 
cómputo municipal verde de Madrid asciende hasta el 25,43 \% (Figura 7), cifra en consonancia con la aportada por Morcillo San Juan et al. (2019).

En el resto de distritos la distribución de la superficie verde parece estar ajustada a las dimensiones de los mismos, salvo el llamativo caso de Villa de Vallecas. El citado caso puede deberse a la presencia de tierras de cultivo de cereal de invierno, o a campos abandonados (barbecho social), entre otras posibles razones. Sin embargo, esa correlación cuanto de más grande/más verde, se rompe al ver los valores superficiales porcentuales, de forma que son los distritos Moncloa-Aravaca (38.2\%), Retiro (24.5\%), Hortaleza (17.1\%), Usera (16.5\%) y Arganzuela (14.5\%) los de mayor valor superficial. Estos distritos arrojan mayor porcentaje de espacio verde al contar con Parques Históricos Municipales (Parque del Oeste-Dehesa de la Villa en el distrito de Moncloa Aravaca; Jardines del Buen Retiro, Retiro en el distrito del mismo nombre), Parques Singulares (Juan Pablo II en el distrito Hortaleza) o Parque Rústico Forestal como la Casa de Campo, de una gran importancia superficial dentro del distrito Moncloa Aravaca.

Figura 7. Espacio verde absoluto y relativo en los distritos del municipio de Madrid

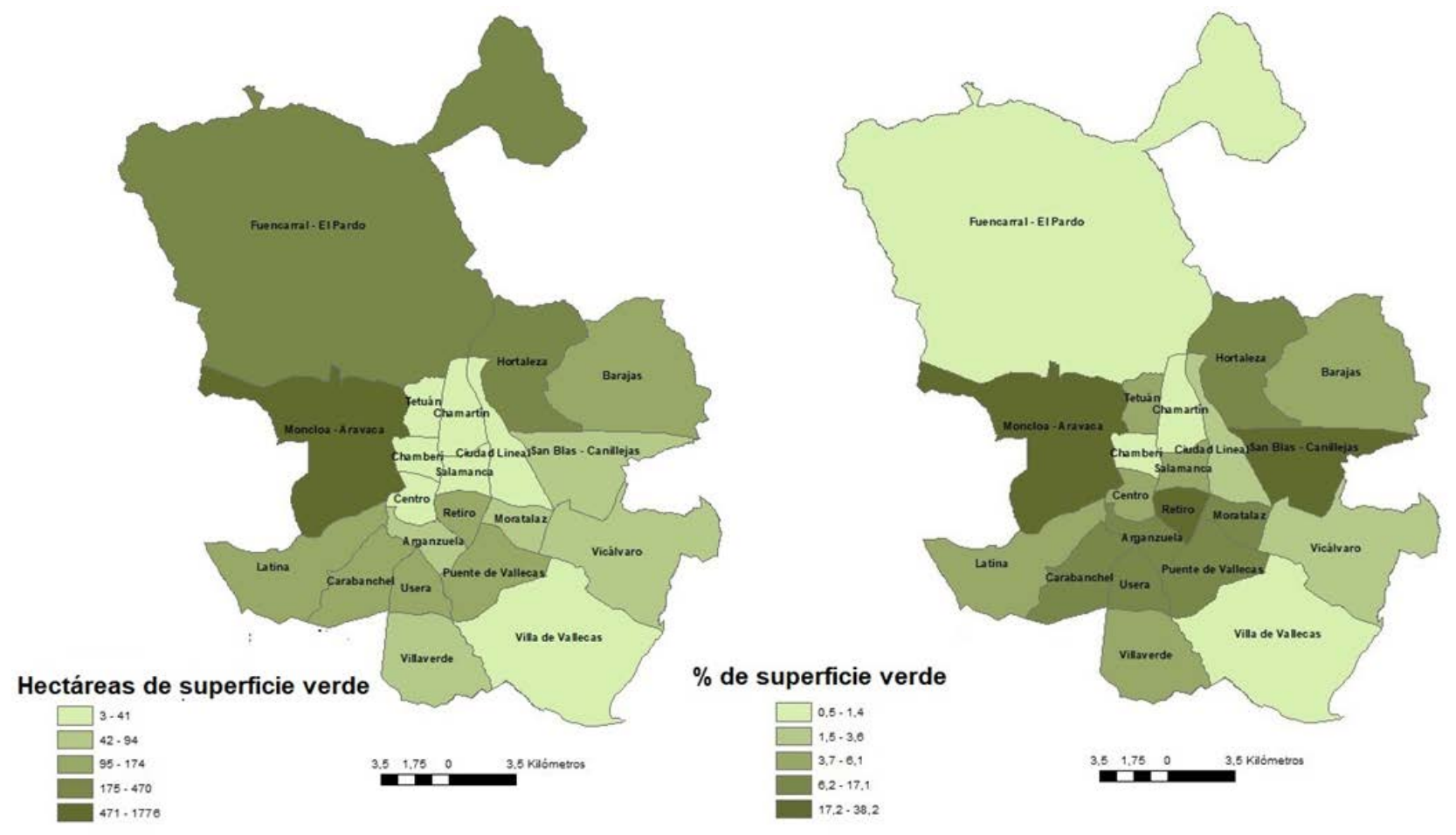

Fuente: elaboración propia a partir de Ayuntamiento de Madrid (2020)

Como más adelante se señala, todo este espacio verde ha sufrido los daños de la fuerte nevada y la persistencia de varios días de los acúmulos de nieve; sin embargo, es el arbolado el que en 
primera instancia parece ser el más agredido. En la Figura 8 se muestra los detalles de la nieve acumulada en la ciudad y los impactos directos en el arbolado del viario urbano (8a) y de los dos grandes parques del Municipio: Casa de Campo (Figura 8b) y Monte de El Pardo (Figura 8c). En las fotos panorámicas de estos dos pulmones de la ciudad de Madrid solo se aprecia la alta densidad forestal perennifolia (fotos centrales $8 b$ y 8c), pero en detalle se advierten la ingente cantidad de arbolado y ramas caídas tras el paso de Filomena. Así, en el informe que el Ayuntamiento de Madrid remite a la Delegación del Gobierno relativo a las reparaciones de daños, las mayores partidas son para pavimento, aceras y arbolados. De los 279 millones de euros estimados para dichas reparaciones, se calculan 74 millones de euros sólo para reposición de "arbolado de las zonas verdes", y 36 millones para la talas y podas exigidas por seguridad (La Razón, February 16, 2021).

Figura 8. Nieve acumulada por la borrasca Filomena e impactos en el arbolado Figura 8a. Ejemplos de la nieve en el viario urbano
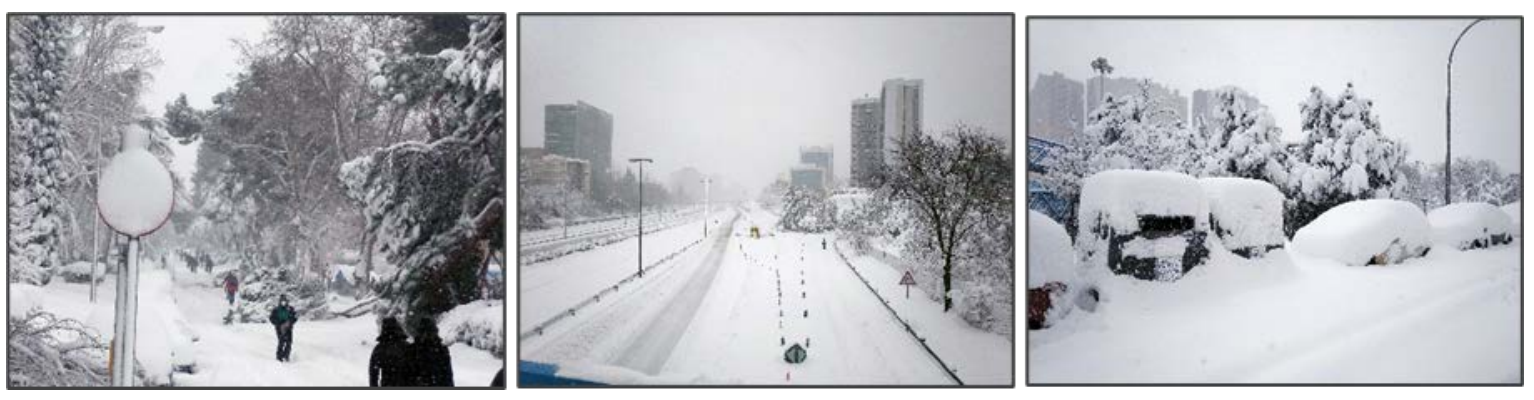

Figura 8b. Vista panorámica de la Casa de Campo (centro) y detalles de la caída de arbolado
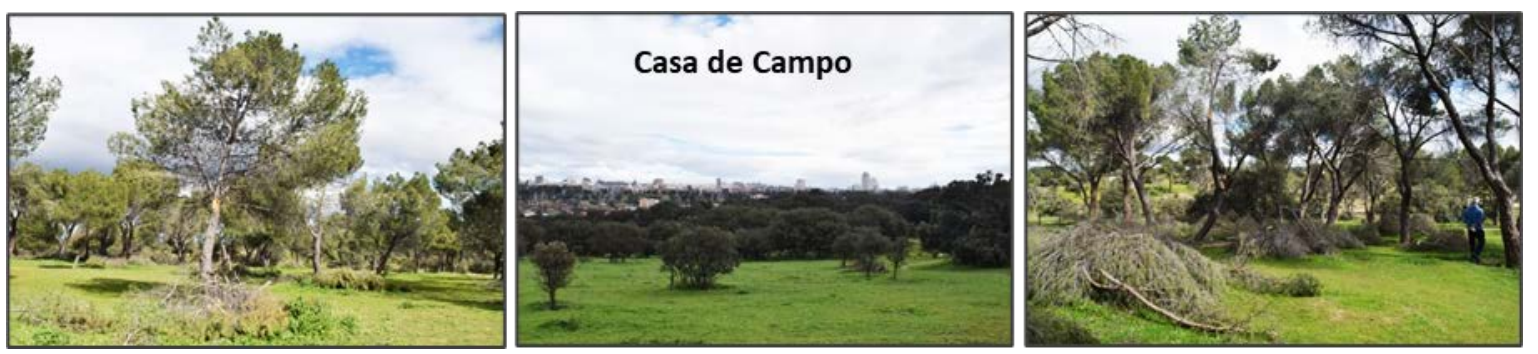

Figura 8c. Vista panorámica del Monte de El Pardo (centro) y detalles de la caída de arbolado
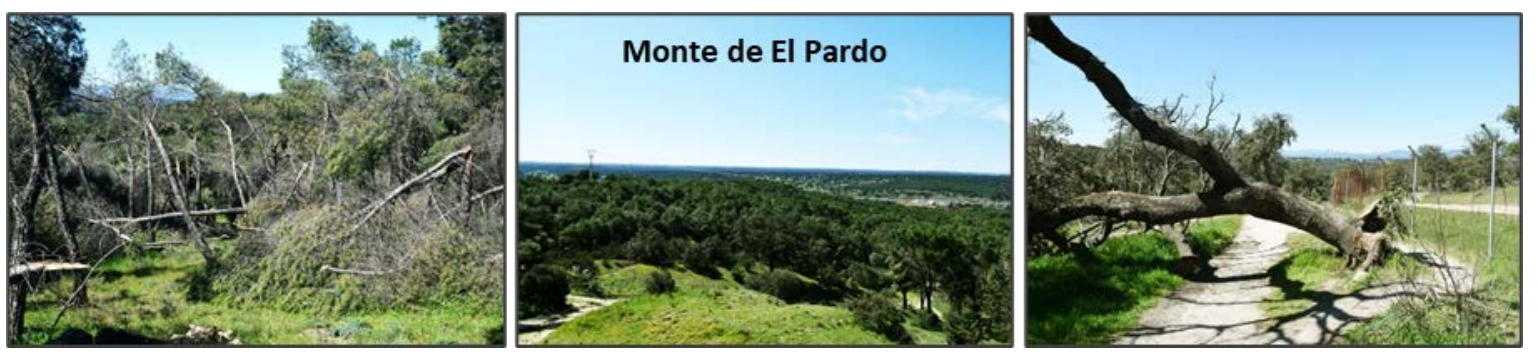

Fuente: elaboración propia (9-10 de enero de 2021, marzo de 2021) 
La gran recurrencia de imágenes Sentinel 2 (gracias a que se dispone de los dos satélites Sentinel 2-A y 2-B) permite conocer la extensión de la cobertura vegetal anterior a la nevada (6-01-2021) y las áreas afectadas por la nieve (11-01-2021), (Figura 9).

En la imagen en falso color bandas 11-8-4 (R-G-B) se han combinado las regiones del espectro correspondientes al infrarrojo medio, infrarrojo cercano y rojo. En la fecha anterior a la nevada esta combinación de bandas resalta en verde las cubiertas que tienen más actividad clorofílica. Así, de la primera fecha se representa en verde, más o menos oscuro según la densidad, la superficie de vegetación perennifolia (mayoritariamente Pinus pinea, Quercus ilex y Pinus halepensis, junto a su orla arbustiva asociada), ocupando amplias extensiones en el norte del municipio, en el Monte del Pardo y de Viñuelas y en el oeste en la Casa de Campo; en verdes claros herbáceas terófitas, céspedes (campos de golf y privados) diseminados por toda la imagen y algunos regadíos localizados en las riberas de los ríos; en tonos azulados y violáceos el entramado urbano y vías de comunicación y, por último, los suelos desnudos en tonos claros (blanquecinos y rosados) que corresponden en parte a cultivos de secano que en el mes de enero aún no se han desarrollado, a parcelas en barbecho y a terrenos que se están empezando a urbanizar, como se observa en la parte inferior de la imagen. Hay que destacar que en esta imagen no se pueden discriminar bien las especies caducifolias al carecer de hojas en el mes de enero y, por tanto, tener una baja actividad clorofílica. En la imagen del 11-01-2021, la superficie del área metropolitana de Madrid se divide en tres categorías: manto de nieve (blanco), edificaciones e infraestructuras viarias (tonos grises) y vegetación libre de nieve (tonos verdes). En esta imagen se advierte que parte de la superficie arbolada queda libre de nieve, pues inicialmente esta queda retenida en algunas ramas, que en muchos casos no soportan el peso adicional y terminan por caer, arrastrando a veces a todo el árbol. No obstante, es visible la gran extensión del manto nival en todo el municipio de Madrid, que afectó tanto a las zonas forestales y orla periurbana, con las temperaturas superficiales más bajas $\left(-11^{\circ} \mathrm{C}\right.$ a $\left.-7,5^{\circ} \mathrm{C}\right)$, como al interior de la ciudad, dado que también se mantuvo bajo cero más de una semana (Figura 6).

Sin duda, el gran grosor del manto de nieve que cubrió numerosos, cuando no todos, los espacios verdes de características muy variadas y su persistencia en forma de helada han debido tener consecuencias diferentes para los individuos y especies que componen dichos elementos urbanos de vital importancia, como son el arbolado caducifolio, el perennifolio -cuyos daños son más patentes y fáciles de visualizar-, numeroso arbolado de jardinería, tanto de espacios amplios como árboles de alineación viaria, en general de naturaleza alóctona, setos, céspedes y pastizales, etc. Un elemento diferenciador de ese impacto está sin duda en la fisiología y la 
morfología de las plantas que los conforman en relación con el cuadro meteorológico vivido en los referidos días, en su adaptación o no al medio natural y a la rareza de este evento meteorológico en nuestro medio.

Figura 9. Imágenes Sentinel 2. Izquierda: en falso color 11-8-4 RGB de 6-01-2021 anterior a la nevada; derecha: de 11/01/2021, posterior a la misma
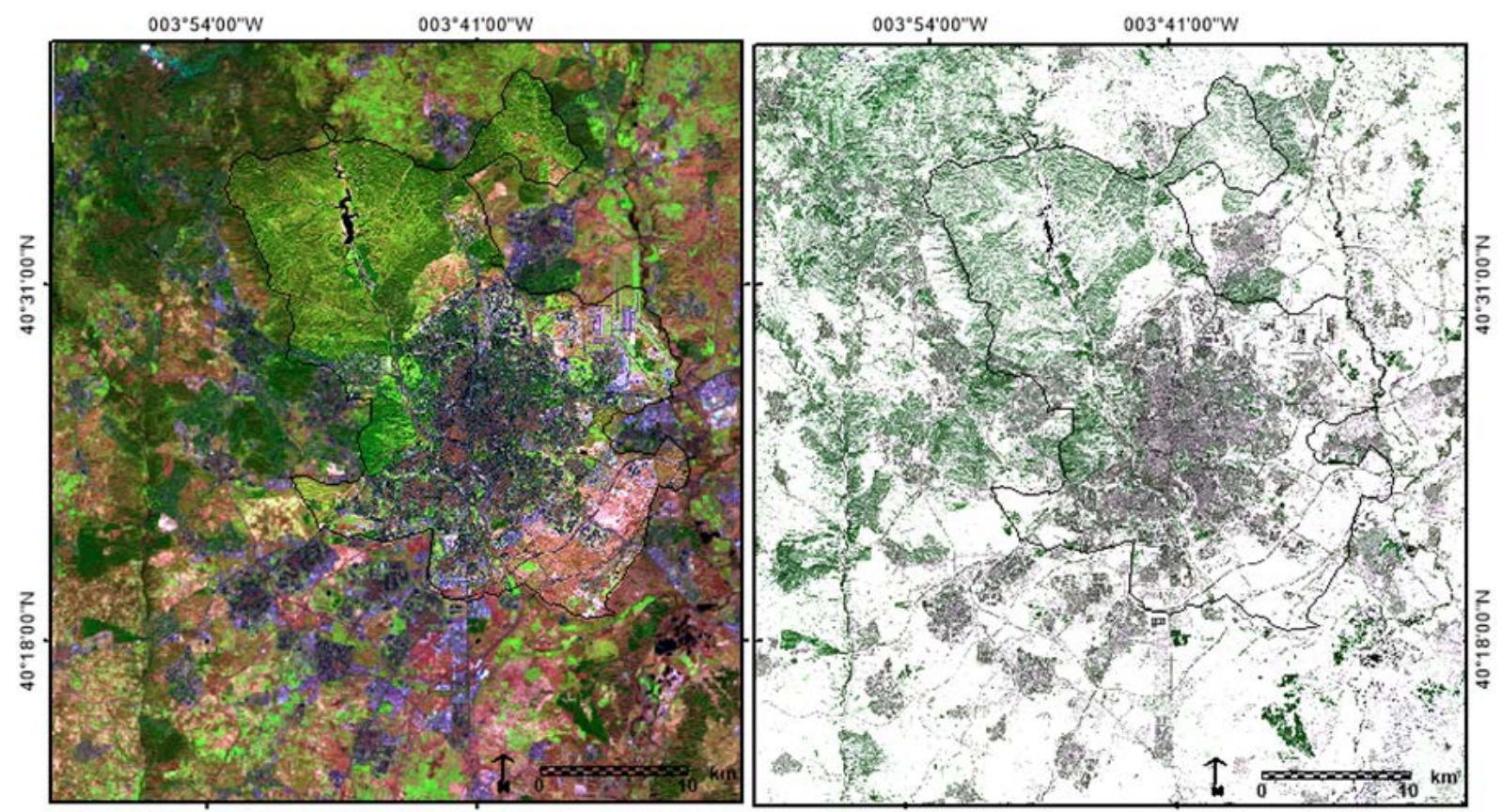

$003^{\circ} 54^{\circ} 00^{\circ} \mathrm{W}$

$003^{\circ} 41^{\circ} 00^{\circ} \mathrm{W}$

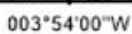

$003^{\circ} 41^{\circ} 00^{\prime \prime} \mathrm{W}$
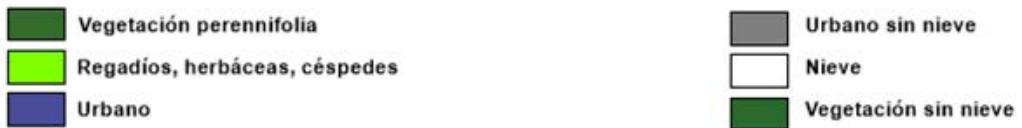

Fuente: elaboración propia a partir de Copernicus Sentinel Hub (2021)

En principio, el impacto físico más visible ha sido la caída de ramas y pies arbóreos por el peso de acumulación de la nieve, más que por la violencia de viento, siendo esta última causa la más frecuente en los temporales que afectan al arbolado de Madrid de manera ordinaria. Esta presión se vio agravada por la posterior congelación de la nieve, que supuso el mantenimiento del peso ejercido en copa y ramas durante más tiempo. A esta merma directa del arbolado hay que sumarle las intensas talas y cortas forzadas posteriores, ante el inminente riesgo para la población o de la propia viabilidad del arbolado. Estas labores se prolongan en la ciudad durante varios meses, actuando primero en el arbolado viario, para acometer después los numerosos parques urbanos y áreas forestales. En los espacios de mayor tamaño (Monte de El Pardo y Casa de Campo), es tal el volumen de material a retirar que tras cuatro meses del evento todavía quedan muchas evidencias del daño ocasionado, que tardará años en recuperarse. 
Entre las especies arbóreas que componen los bosquetes, parques, jardines, y forman parte del callejero de Madrid, las más perjudicadas por el soporte de la nieve han sido lógicamente por las fechas, las coníferas. Entre ellas, las más afectadas han sido los pinares, también los más abundantes (Pinus pinea y $P$. halepensis), con una pérdida notable de pies y ramaje en algunos barrios de la ciudad, y Cuppresus sp., más por el doblaje de sus ramas que por la caída de individuos. En menor medida también se han visto afectados abetos y cedros, ya que su fisonomía piramidal y disposición del ramaje más abierto, les confiere mejor adaptación al peso de la nieve. En algunos parques y jardines privados no son despreciables las pérdidas por congelación de algunas especies alóctonas y exóticas en Madrid (familias Arecaceae, Agavaceae o Cactaceae), pero cuantitativamente son muy minoritarias.

En el Monte de El Pardo la pérdida es notable en los encinares, lo que se suma a daños pasados por motivos fitosanitarios, que originaron una elevada seca (Hurtado Hernández et al., 2018). No obstante, en este monte el impacto tiene mayor intensidad en los sectores de repoblaciones de Pinus pinea, con caída masiva de ejemplares y millares de ramas (Figuras 8 y 10).

La estimación de pérdida de biomasa vegetal tras el paso de la Borrasca Filomena en Madrid se ha obtenido partir de las imágenes de cambios del índice de vegetación (NDVI). La imagen obtenida es la que se muestra en la Figura 10, en la que se han resaltado en tonos rojos las áreas en las que ha disminuido de forma considerable la vegetación. Por tanto, las áreas más afectadas por el paso de Filomena se corresponden fundamentalmente al arbolado perennifolio y muestran un intenso impacto en todo el municipio. Sin embargo, hay sectores que han sido especialmente castigados, entre los que cabe destacar algunos ejemplos (Figura 10):

- Encinares y pinares al norte del municipio (Finca de tres Cantos - Monte de Viñuelas), en las exposiciones de umbría, pues son las que albergaron temperaturas gélidas durante más tiempo, con $-10^{\circ} \mathrm{C}$ a $-13^{\circ} \mathrm{C}$ en superficie (1, Figura 10). Aquí en numeroso arbolado de gran porte se troncharon muchas ramas y otros tantos cayeron, por lo que el impacto tardará décadas en recuperarse, aún con las acciones de restauración que Ayuntamiento o Patrimonio puedan realizar.

- Las pérdidas del arbolado en el viario urbano afectan lógicamente a los barrios con más coníferas, predominantes al E y NE del municipio (distritos de Ciudad Lineal y Hortaleza) (2, Figura 10), pero también a los pinares de las márgenes de una de las arterias de comunicación principales, la M-30 y otros viales que presentan flancos en talud, en muchos lugares "acarcavados" por la posterior fusión del hielo. Un gran número de árboles ubicados 
en estas pendientes y en suelos pocos profundos han caído por el propio deslizamiento de partes de dichos taludes. Con ello se pierde parte de esta pantalla acústica para las viviendas limítrofes, deteriorando la calidad ambiental de las mismas.

- Al SE y S del municipio las notables pérdidas de vegetación afectaron a herbáceas terófitas, de mejor recuperación, pero también a coníferas relativamente jóvenes del Pinar de Santa Eugenia y Parque forestal de Entrevías (3, Figura 10). En este sector se encuentra el Cerro Grande de Almodóvar, un hito geológico, paleontológico y cultural y un mirador excelente del SE madrileño, hoy el kilómetro cero del futuro Bosque Metropolitano de Madrid, (Ayuntamiento de Madrid, 2021a) y que, si bien su ausencia de arbolado le libró del daño aquí estudiado, el pinar que le antecede y bordea por el este y parte norte sufrió importantes daños.

- Pinares de repoblación del Monte de El Pardo y Casa de Campo, con alta densidad (4 y 5, Figura 10 y Figuras $8 b$ y $8 c)$.

En estos ejemplos, y de manera general en todos los parques con predominio de coníferas, los daños son muy intensos donde el soporte del arbolado estaba más comprometido, por estar en pequeñas pendientes, o junto a sendas y caminos, con suelos muy degradados (arenosoles y regosoles fundamentalmente) y con un sustrato fácilmente alterable, como es el caso de las arcosas, dominantes en el centro y norte del municipio, o los yesos del sur y sudeste. Los daños también han sido acusados en los sectores de pinares de repoblación con alta densidad, cayendo a modo de dominó en algunas laderas (Figura 8c). En general, el impacto en el arbolado queda representado por tramos rojos muy estrechos y rectilíneos en la imagen de cambios del NDVI (Figura 10).

Los cálculos e imágenes obtenidos a partir del NDVI de las imágenes multiespectrales de resolución media ofrecen información sobre la respuesta de vegetación muy precisa en su localización espacial (Mizutani et al., 1991; Krüger et al., 2018), pero que no permiten su diferenciación por estratos, salvo la obtenida de la interpretación derivada del patrón espacial (parcelas de cultivo, campos de golf, praderas, forestales, etc.). Es por ello que las imágenes con 10 m de resolución espacial no resultan adecuadas para ofrecer una valoración cuantitativa por distritos, pues el arbolado perennifolio ofrece una respuesta espectral similar a los setos vivos y parte del coronario arbustivo mediterráneo. Para ello, sería necesario utilizar imágenes de mayor detalle, que permitan una clasificación más precisa (Krüger et al., 2018) o imágenes lidar, que discriminen la vegetación por alturas (Morcillo San Juan et al., 2019), aspecto que podrá tratarse en investigaciones futuras. 
Figura 10. Pérdida de vegetación en el municipio de Madrid y detalles en diferentes sectores, obtenida mediante la imagen de cambios en el NDVI entre febrero de 2020 y 2021
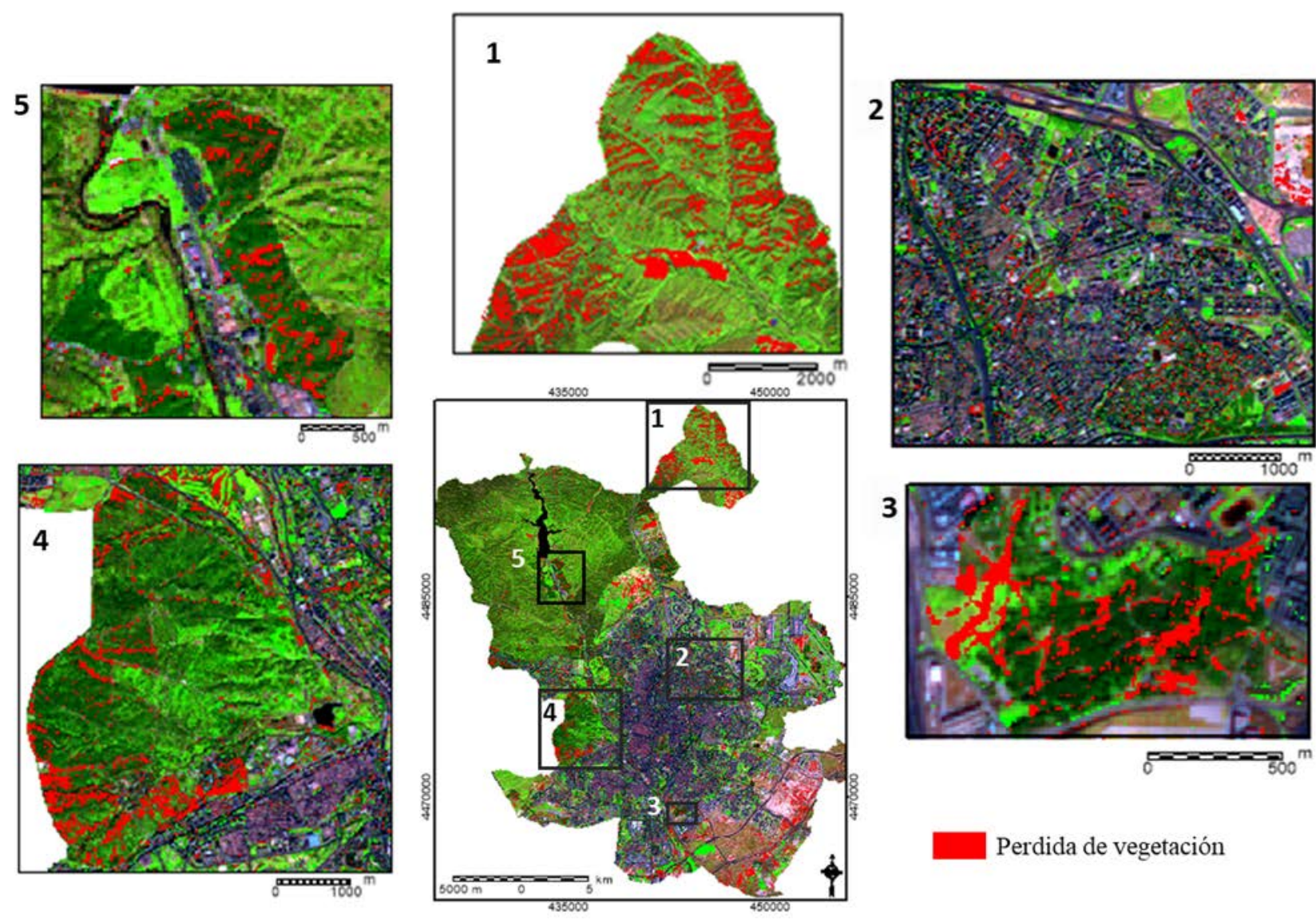

Perdida de vegetación

Fuente: elaboración propia a partir de Copernicus Sentinel Hub (2021)

Apuntar de modo aproximativo que según los datos calculados a partir de las imágenes de satélite el municipio de Madrid pierde en torno al $11 \%$ de su cobertura vegetal de invierno, ascendiendo al $14 \%$ en los distritos con los dos grandes pulmones de la ciudad: El Monte de El Pardo y la Casa de Campo. No obstante, las cifras aquí obtenidas están en consonancia con las ofrecidas por el Ayuntamiento de Madrid (2021b), que calcula los daños en el arbolado por Filomena en 800000 ejemplares (cerca del $14 \%$ de los 5700000 árboles de Madrid), de los que unos 80000 cayeron y el resto perdió gran parte del ramaje. Ante esta pérdida, la mayoría en la Casa de Campo (unos 60000 árboles), el Ayuntamiento proyecta realizar la mayor plantación de arbolado de su historia para reparar el $10 \%$ de los ejemplares afectados, que cayeron o han tenido que ser talados. 


\section{Conclusiones}

Las características de la borrasca Filomena y las consecuencias más destacadas en el arbolado de Madrid son:

- La extensión de nieve alcanzada en la Península lbérica, unos 256000 km², se ha podido representar por primera vez en detalle gracias a las imágenes del satélite y combinaciones de los canales visibles e infrarrojos medios. De los muchos satélites e imágenes en falso color posibles, las de Terra/MODIS, en la combinación de bandas 3-6-7, son las que ofrecen una mejor interpretación, al registrar el manto nival en rojo. Frente a esta combinación la imagen MODIS en color natural (RGB 1-4-3), muy utilizada para el seguimiento de la nubosidad, no resulta adecuada para detectar la cobertura nival, al visualizarse ambos elementos en blanco.

- La altura de nieve alcanzada en la ciudad de Madrid $(52,9 \mathrm{~cm})$ no tiene precedentes en el último siglo, por lo que se considera rara y extraordinaria, aunque sí ha sucedido en el mes de mayor riesgo de nevada (enero) en el centro peninsular.

- La permanencia del manto nival en Madrid durante unos diez días responde tanto a la cantidad caída como a las características sinópticas posteriores que condicionaron una gran estabilidad atmosférica. En consecuencia, se produjo una intensa inversión térmica que dejó gran parte del municipio de Madrid con temperaturas superficiales gélidas $\left(\mathrm{de}-13^{\circ} \mathrm{C}\right.$ a $\left.-2,5^{\circ} \mathrm{C}\right)$, y menos rigurosas en la Sierra $\left(\right.$ de $-2,5^{\circ} \mathrm{C}$ a $\left.4^{\circ} \mathrm{C}\right)$. Gracias a la paralización del tráfico provocado por el manto nival en buena parte del área metropolitana de Madrid esta inversión térmica no dio lugar a altos niveles de contaminación.

- Por la fecha del episodio nival los árboles más perjudicados han sido las coníferas debido a que al mantener las hojas retienen más cantidad de nieve. Entre ellas, las más afectadas han sido los pinares, también los más abundantes (Pinus pinea y $P$. halepensis), con una pérdida notable de pies y ramaje, y cipreses (Cupressus sp.), más por el doblaje de sus ramas que por la caída de individuos. En menor medida también se han visto afectados algunos abetos y cedros, ya que su fisonomía piramidal y disposición del ramaje más abierto, les confiere mejor adaptación al peso de la nieve. En algunos parques, jardines privados y viveros no son despreciables las pérdidas por congelación de algunas especies alóctonas y exóticas en Madrid (familias Arecaceae, Agavaceae o Cactaceae) que han supuesto altos costes económicos todavía sin evaluar, pero cuantitativamente en el conjunto del municipio son muy minoritarias. En el Monte de El Pardo y Casa de Campo la pérdida es también considerable en los encinares (Quercus ilex). 
- En general, en todos los parques con predominio de coníferas, independientemente de su ubicación, los daños han sido muy intensos donde el soporte del arbolado estaba más comprometido, por estar en pendientes, o junto a sendas y caminos, donde los suelos están muy degradados (arenosoles y regosoles fundamentalmente) y el sustrato es fácilmente alterable, como sucede en las arcosas que dominan en buena parte del centro y norte del municipio de Madrid.

- Aunque es difícil calcular la masa forestal dañada por la acumulación de nieve, una primera estimación en el municipio de Madrid elaborada mediante cambios del NDVI de las imágenes Sentinel 2-a y 2-b y la verdad terreno arroja una pérdida en torno al 11 \% de la cobertura vegetal del invierno, ascendiendo al $14 \%$ en los distritos con los dos grandes pulmones de la ciudad: El Monte de El Pardo y la Casa de Campo. En ambos, el daño es máximo en los sectores de repoblaciones de pinares, con alta densidad y suelos degradados por pisoteo, tránsito de bicicletas y de caballos (caso de El Monte de El Pardo).

- El uso combinado de imágenes de satélite de diferentes resoluciones espaciales (TERRA/MODIS, Landsat 8 y Sentienel 2), ha permitido conocer mejor el alcance de esta nevada extraordinaria y estimar algunos impactos en el arbolado perennifolio. Sin embargo, para evaluar las pérdidas reales se precisa de imágenes de satélite de mayor resolución espacial, vuelos fotogramétricos o imágenes lidar actuales y de detalle, aspecto que se será conveniente realizar cuando finalicen las tareas de corta y retirada del material arbóreo dañado.

- Como problema metodológico esencial se debe señalar la enorme dificultad para conocer y cartografiar con exactitud la cuantía del arbolado previo a la borrasca de Madrid, ya que las distintas fuentes disponibles discrepan entre sí, pues en Madrid confluyen numerosas competencias yuxtapuestas, y en consecuencia, con variedad de gestión, producción y distribución de la información, que hacen especialmente complejo recopilar toda la información sobre el conjunto de los espacios verdes.

- Por último, cabe plantearse si este riesgo inusual, al menos hasta el momento, que ha afectado al arbolado perennifolio natural o naturalizado es suficiente para apostar por reposiciones con especies caducifolias más demandantes de agua, en una ciudad de larga sequía estival (4 meses de media) y a riesgo de sequías. Tienen a su favor los mayores beneficios aportados al clima urbano (amortiguación térmica y humedad) y a la calidad del aire, por el papel desempeñado como filtro de aerosoles en épocas de follaje. Sin duda, la pérdida notable de arbolado perennifolio tras el paso de Filomena deja a Madrid menos 
protegida ante los frecuentes episodios de contaminación invernal. Como efecto positivo inicial se destaca una mayor iluminación en algunas calles y espacios verdes urbanos, aunque previsiblemente se tornarán en poco tiempo en incrementos de las temperaturas y de la isla de calor urbana, que no serán compensadas por las reposiciones de pies arbóreos, al menos hasta pasadas unas décadas.

- Por último, quiere dejarse señalado que desconocemos la afección precisa de este fenómeno climatológico adverso en otros espacios urbanos del país. Si bien como se ha mostrado afectó casi a un cuarto de millón de $\mathrm{km}^{2}$, especialmente en la zona centro, parece que las ciudades más afectadas, junto a Madrid, fueron Toledo, Guadalajara, y en menor medida Ávila, Segovia y Zaragoza. Sería interesante abordar este aspecto en un marco más amplio y aplicar fuentes de mayor resolución para un mejor conocimiento geográfico de los efectos de estos sucesos extraordinarios.

Agradecimientos: Este trabajo ha sido financiado por el Proyecto "Actualización de la susceptibilidad y riesgo de inundación en áreas selladas de la Comunidad de Madrid y áreas limítrofes: estudio de casos y propuestas de mejora". Banco Santander - UCM, 2021-2022, PR108/20-24.

Declaración responsable: Las/os autoras/es declaran que no existe ningún conflicto de interés con relación a la publicación de este artículo. Los apartados 1, 2 y el trabajo de campo han sido realizados de forma conjunta por las/os tres autoras/es. Los apartados 3 y 4 fueron redactados por $M^{a} E$. Pérez y J.Ma . García. Las figuras y tablas sobre aspectos climáticos y de imágenes de satélite han sido elaboradas por $M^{2} E$. Pérez, las relativas a la distribución municipal del arbolado las ha elaborado J.Mª. García, y los aspectos biogeográficos han sido redactados por Mª. García. El apartado de conclusiones fue elaborado por las/os tres autoras/es, al igual que la consulta y selección de bibliografía. 


\section{Bibliografía}

AEMET (2021). Borrascas 2020-2021.

https://www.aemet.es/es/conocermas/borrascas/2020-

2021/estudios_e_impactos/filomena\#enlaces_asociados

Almendros Coca, M.A. (1992). Climate features of Retiro park, Madrid. Aspectos climáticos del parque del Retiro (Madrid). Estudios Geográficos, 53(207), 217-239.

Alonso, R., Vivanco, M.G., González-Fernández, I., Bermejo, V., Palomino, I., Garrido, J.L., \& Artínano, B. (2011). Modelling the influence of peri-urban trees in the air quality of Madrid region (Spain). Environmental Pollution, 159(8-9), 21382147. https://doi.org/10.1016/j.envpol.2010.12.005

Aram, F., Solgi, E., García, E. H., Mosavi, A., \& Várkonyi-Kóczy, A. R. (2019). The cooling effect of large-scale urban parks on surrounding area thermal comfort. Energies, 12(20) https://doi.org/10.3390/en12203904

Ayuntamiento de Madrid (2020). Inventario de las zonas verdes en la ciudad de Madrid. https://tinyurl.com/2rsv6h5j

Ayuntamiento de Madrid (2021a). Proyecto de Bosque metropolitano. https://tinyurl.com/56zzj3ta

Ayuntamiento de Madrid (2021b). Almeida presenta el Plan de Acción para la recuperación del arbolado tras Filomena y anuncia la plantación de 100.000 ejemplares. https://www.madrid.es/portales/munimadrid/es/

Bernatzky, A. (1982). The contribution of tress and green spaces to a town climate. Energy and Buildings, 5(1), 1-10. https://doi.org/10.1016/0378-7788(82)90022-6

Blancher, G. (1963). Urban green spaces. Revue d'Hygiène Et de Médecine Sociale, 11, 219-237 Bowler, D.E., Buyung-Ali, L., Knight, T.M. \& Pullin, A.S. (2010). Urban greening to cool towns and cities: A systematic review of the empirical evidence. Landscape and Urban Planning, 97(3), 147-155. https://doi.org/10.1016/j.landurbplan.2010.05.006

Calzada P., \& Iglesias-Díaz, M.I. (2016). El riesgo del arbolado urbano. Contexto, concepto y evaluación. Mundiprensa.

Cañada Torrecilla, R. (2017). Clasificación de tipos de tiempo y su influencia en las concentraciones de dióxido de nitrógeno, material particulado (pm 10 ) y ozono en la ciudad de 
Madrid, España. Boletín de la Asociación de Geógrafos Españoles, (75), 447470. https://doi.org/10.21138/bage.2508

Coates, U.A. (1955). Urban congestion and green belts. The Journal of the Royal Society for the Promotion of Health, 76(9), 542-548. https://doi.org/10.1177/146642405507600903

Comisión Europea, EU. (2014). Construir una Infraestructura Verde Para Europa. Estrategia Nacional de Infraestructura Verde y de la Conectividad y Restauración Ecológicas https://ec.europa.eu/environment/nature/ecosystems/docs/GI-Brochure-210x210ES-web.pdf

Comunidad de Madrid (2019). Memoria del Mapa digital continuo de vegetación de la Comunidad de Madrid.

https://www.comunidad.madrid/sites/default/files/aud/urbanismo/cma_urb_es_memoria_ma pa_vegetacion.pdf.

Comunidad de Madrid (2020). Ecosistemas forestales. https://www.comunidad.madrid/servicios/urbanismo-medio-ambiente/ecosistemasforestales

Copernicus Sentinel Hub (2021). Imágenes de satélite Sentinel 2. https://scihub.copernicus.eu/dhus/\#/home

Du, H., Zhou, F., Cai, Y., Li, C., \& Xu, Y. (2021). Research on public health and well-being associated to the vegetation configuration of urban green space, a case study of Shanghai, China. Urban Forestry Und Greening, 59(126990). https://doi.org/10.1016/j.ufug.2021.126990

Fernández García, F. (1986). El clima de la Meseta Meridional: los tipos de tiempo. UAM Ediciones.

Fernández García, F., Almendros Coca, M.Á., \& López Gómez, A.L. (1996). La influencia del relieve en la isla de calor de Madrid: Las vaguadas del Manzanares y del Abroñigal. Estudios Geográficos, (224), 473-494. https://doi.org/10.3989/egeogr.1996.i224

Fernández García, F., Allende Álvarez, F., Rasilla Álvarez, D., Martilli, A., \& Alcaide Muñón, J. (2016). Estudio de detalle del clima urbano de Madrid. Área de Gobierno de Medio Ambiente y Movilidad. Ayuntamiento de Madrid. 
Gago, E. J., Roldan, J., Pacheco-Torres, R., \& Ordóñez, J. (2013). The city and urban heat islands: A review of strategies to mitigate adverse effects. Renewable and Sustainable Energy Reviews, 25, 749-758. https://doi.org/10.1016/j.rser.2013.05.057

Gál, T., Mahó, S.I., Skarbit, N., \& Unger, J. (2021). Numerical modelling for analysis of the effect of different urban green spaces on urban heat load patterns in the present and in the future. Computers, Environment and Urban Systems, 87. https://ma.xmol.com/paperRedirect/1354164608240115712

García Alvarado, J.M., Pérez González, M.E., \& García Rodríguez, M.P. (2020). Sellado de suelos, fragmentación y conectividad ecológica en la conurbación de Madrid (España). Boletín de la Asociación Española de Geografía, (85). https://doi.org/10.21138/bage.2884

Gómez Mendoza, J. (1995). Cultura ambiental tradicional y arbolados de Madrid. Anales de Geografía de la Universidad Complutense, 15, 361-373.

Gómez Mendoza, J. (2003). El gobierno de la naturaleza en la ciudad. Ornato y ambientalismo en el Madrid decimonónico. Real Academia de la Historia.

González Granados, J. (2011). Flora y vegetación gipsícola, halófila y nitrófila de Madrid. Foresta, 52, 46-57.

Hurtado Hernández, A., Hiernaux Candelas, L., Tome de la Vega, F., Huidobro Ruiz, A., \& Muñoz Rodríguez, Á. (2018). Estudio de caracterización de daños compatibles con 'la seca' de la encina en el Monte del Pardo y propuesta de actuaciones. Phytoma España, 301, 50-

61. https://www.inffe.es/pdf/INFFE_Danos_compatibles\%20con_la_Seca_en_El\%20Pardo_201 $\underline{\text { 8.pdf }}$

Hussain, M., Chen, D., Cheng, A., Wei, H., \& Stanley, D. (2013). Change detection from remotely sensed images: From pixel-based to object-based approaches. Journal of Photogrammetry and Remote 91 106. https://doi.org/10.1016/j.isprsjprs.2013.03.006

IGME (1971). Mapa Geológico de España, Escala 1:200.000. Departamento de Publicaciones del Instituto Geológico y Minero de España.

IGN (2021). Plan Nacional de Ortofotografía Aérea. https://pnoa.ign.es/

Jiménez-Muñoz, J.C., Sobrino, J.A., Skokovic, D., Mattar, C., \& Cristobal, J. (2014). Land surface temperature retrieval methods from landsat-8 thermal infrared sensor data. IEEE Geoscience and Remote Sensing Letters, 17(10), 1840-1843. https://doi.org/10.1109/LGRS.2014.2312032 
Krüger, T., Hecht, R., Herbrich, J., Behnisch, M., \& Oczipka, M. (2018). Investigating the suitability of Sentinel-2 data to derive the urban vegetation structure. Paper presented at the Proceedings of SPIE - the International Society for Optical Engineering, 10793. https://doi: $10.1117 / 12.2325337$

Kweon, B.S., Sullivan, W.C., \& Wiley, A.R. (1998). Green common spaces and the social integration of inner-city older adults. Environment and Behavior, 30(6), 832858. https://doi.org/10.1177\%2F001391659803000605

La Razón (2021). Daños en las instalaciones municipales de Madrid de la borrasca Filomena. Diario La Razón. https://www.larazon.es/madrid/20210216/ndx4egufnvbslnsccacxoij34u.html

Nicholson, E. (1979). Nature in Cities: The natural environment in the design and development of urban green space. Edited by lan C. Laurie. Cambridge University Press. https://doi.org/10.1017/S003060530002439X

Lemus-Canovas, M., Martin-Vide, J., Moreno-García, M.C., \& López-Bustins, J.A. (2020). Estimating Barcelona's metropolitan daytime hot and cold poles using Landsat-8 land surface temperature. Science of the Environment, 699. https://doi.org/10.1016/j.scitotenv.2019.134307

Livesley, S.J., McPherson, E.G., \& Calfapiedra, C. (2015). The Urban Forest and Ecosystem Services: Impacts on Urban Water, Heat, and Pollution Cycles at the Tree, Street, and City Scale. Journal of Environmental Quality, 45, 119-124. https://doi.org/10.2134/jeq2015.11.0567

Maimaitiyiming, M., Ghulam, A., Tiyip, T., Pla, F., Latorre-Carmona, P., Halik, T., \& Caetano, M. (2014). Effects of green space spatial pattern on land surface temperature: Implications for sustainable urban planning and climate change adaptation. ISPRS Journal of Photogrammetry and Remote Sensing, 89, 59-66. https://doi.org/10.1016/j.isprsjprs.2013.12.010

Mizutani, N., Miyamoto, H., Hayakawa, S., Kato, M., \& Kamigawara, K. (1991). Analysis of green area change in and around metropolis using LANDSAT and census data. Paper presented at the Digest - International Geoscience and Remote Sensing Symposium (IGARSS) (pp. 2359-2362).

Morcillo San Juan, A., Borrajo Millán, J.M., Rastrollo Gonzalo, A., \& Nowak, D.J. (2019). Valor del Bosque Urbano de Madrid. Ayuntamiento de Madrid. https://www.madrid.es/UnidadesDescentralizadas/ZonasVerdes/TodoSobre/ValorBo squeUrbanoMadrid/Valor\%20Bosque\%20Urbano\%20de\%20Madrid.pdf

NASA (2021). MODIS images. https://worldview.earthdata.nasa.gov/ 
Ng, E., Chen, L., Wang, Y., \& Yuan, C. (2012). A study on the cooling effects of greening in a high-density city: An experience from Hong Kong. Building and Environment, 47(1), 256271. https://doi.org/10.1016/j.buildenv.2011.07.014

Nowak, D.J., Crane, D.E., \& Stevens, J.C. (2006). Air pollution removal by urban trees and shrubs in the United States. Urban Forestry and Urban Greening, 4(3-4), 115 123. https://doi.org/10.1016/j.ufug.2006.01.007

Nowak, D.J., Hirabayashi, S., Bodine, A., \& Hoehn, R. (2013). Modeled PM2.5 removal by trees in ten U.S. cities and associated health effects. Environmental Pollution, 178, 395 402. http://dx.doi.org/10.1016/j.envpol.2013.03.050

Rodríguez Romero, E.J., Sáez de Tejada Granados, C., \& Santo-Tomas Muro, R. (2018). Lookouts as a tool for the valorisation of urban landscape. The case study of Madrid. Lecture Notes in Civil Engineering, 3, 843-851. https://doi.org/10.1007/978-3-319-57937-5_87

Susca, T., Gaffin, S.R., \& Dell'Osso, G.R. (2011). Positive effects of vegetation: Urban heat island and green roofs. Environmental Pollution, 159(8-9), 2119-

2126. https://doi.org/10.1016/j.envpol.2011.03.007

Terán, F., \& Sánchez de Madariaga, I. (1999). Madrid Ciudad Región: Entre la Ciudad y el Territorio, en la segunda mitad del siglo XX. Dirección General de Urbanismo y Planificación Regional, Comunidad de Madrid. http://oa.upm.es/21383/

Tucker, C.J. (1979). Red and photographic infrared linear combinations for monitoring vegetation. Remote Sensing of Environment, 8(2), 127-150. https://doi.org/10.1016/00344257(79)90013-0

Turner, T. (1992). Open space planning in London: From standards per 1000 to green strategy. Town Planning Review, 63(4), 365-386. https://doi.org/10.3828/tpr.63.4.1703v67051278442

Tzoulas, K., Korpela, K., Venn, S., Yli-Pelkonen, V., Kaźmierczak, A., Niemela, J., \& James, P. (2007). Promoting ecosystem and human health in urban areas using green infrastructure: $A$ literature review. Landscape and Urban Planning, 81(3), 167178. https://doi.org/10.1016/j.landurbplan.2007.02.001

USGS (2021). Landsat 8 image, Level 2. https://earthexplorer.usgs.gov

Valor, E., \& Caselles, V. (1996). Mapping land surface emissivity from NDVI: application to European, African, and South American areas. Remote Sensing of Environment, 57, 167184. https://doi.org/10.1016/0034-4257(96)00039-9 
Wetterzentrale (2021). Mapas de superficie y 500 hPa. https://www.wetterzentrale.de/

Wild, C. (1981). Managing the landscape of towns. In B. Clouston \& K. Stansfield (Eds.), Trees in towns: maintenance and management (pp. 128-164). Nichols Pub. Co. 